\title{
PRECURSORS OF TYPICAL AND ATYPICAL \\ ROASTED PEANUT FLAVOR
}

\author{
By \\ JON ALBERT NEWELL \\ II \\ Bachelor of Science \\ Oklahoma State University \\ Stillwater, Oklahoma
}

1963

Submitted to the faculty of the Graduate College of the Oklahoma State University in partial fulfillment of the requirements for the degree of DOCTOR OF PHILOSOPHY July, 1967 


\section{PRECURSORS OF TYPICAL AND ATYPICAL ROASTED PEANUT FLAVOR}

Thesis Approved:

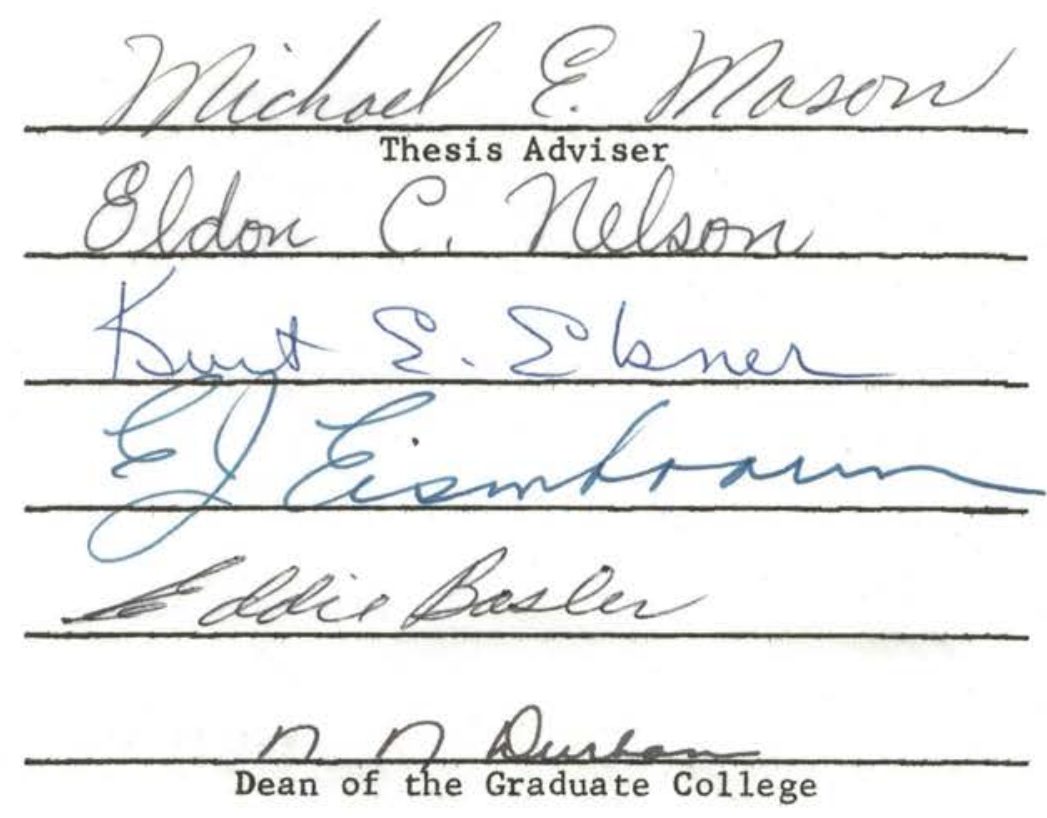




\section{ACHNOWLEDGEMENTS}

The author of this dissertation wishes to express his sincere appreciation to his major adviser, Dr. Michael E. Mason, for his encouragement and counseling during the course of these studies.

The suggestions of Dr. G. V. Odell, Dr. R. S. Matlock, Dr. E. J. Eisenbraun, Dr. E. C. Nelson, Dr. K. E. Ebner and Dr. E. Basler concerning the preparation of the manuscript are also acknowledged.

The author wishes to thank Mrs. Barbara Rutledge who performed amino acid analyses and Mrs. Bonnie Harland who gave technical assistance.

Facilities and equipment for these studies were furnished by the Oklahoma State University Agricultural Experiment Station and the Department of Biochemistry; financial support was derived from a National Institutes of Health Training Grant and a fellowship from the Nestlé Company. 
TABLE OF CONTENTS

Chapter

Page

I. INTRODUCTION . . . . . . . . . . . . . . . . . . . 1

II. LITERATURE REVIEW . . . . . . . . . . . . . . . . . . . . 4

Introduction . . . . . . . . . . . . . . . . . . . . . 4

Precursors of Peanut Flavor . . . . . . . . . . . . . . 5

Peanut F1avor Components . . . . . . . . . . . . . . . 9

Precursors of Chocolate Aroma . . . . . . . . . . . . . 10

Chemistry of Nonenzymatic Browning . . . . . . . . . . 13

Initial Stage--Sugar-Amine Condensation . . . . . 14

Initial Stage--Reaction of $\mathrm{N}$-Substituted

Carbohydrate . . . . . . . . . . . . . . 16

Intermediate Stage of Browning--Dehydration of Sugar Moiety . . . . . . . . . . . . . . . 18

Intermediate Stage of Browning--Fragmentation of Sugar Moiety . . . . . . . . . . . . . . . 18

Intermediate Stage of Maillard Browning-Strecker Degradation. . . . . . . . . . . . . 19

The Final Stages of Browning . . . . . . . . . 20

Flavor Components Produced by Sugar-Amine Reactions . . 21

III. SOME PROPERTIES OF .THE FLAVOR PRECURSOR FRACTION OF

SPANISH PEANUTS . . . . . . . . . . . . . . . . . . . . . 24

Introduction . . . . . . . . . . . . . . . . . . 24

Reagents . . . . . . . . . . . . . . . . 24

Procedure . . . . . . . . . . . . . . . . . . . 25

Preparation of the Flavor Precursor Fraction . . . 25

Comparison of the Yield of Various U1traviolet Absorbing Fractions from Whole Peanut Cotyledons and Peanut Aleurone Grain-Protein Body Fractions . . . . . 26

Determination of Neutral Amino Acids in the Flavor Precursor Fraction . . . . . . . . . . . 26

Separation of Anionic Constituents of the Flavor Precursor Fraction . . . . . . . . . . . 27

Determination of Amino Acids in the Flavor Precursor Fraction Using Ion Exchange and

Paper Chromatography .. . . . . . . . . . 27

Gas Chromatography . . . . . . . . . . . 28

Regeneration of Carbonyls from their 2,4-Dinitrophenylhydrazones . . . . . . . . . 29 
Procedures for the Generation and Identi-

fication of Volatile Compounds from Peanuts, Defatted Peanuts, and the Flavor Precursor

Fraction . . . . . . . . . . . . . . . . . . 29

Preparation of Browning Pigments . . . . . . . . 30

Browning Reactions in Modified Flavor

Precursor Fractions . . . . . . . . . . . . 31

Results and Discussion . . . . . . . . . . . . . 32

IV. PRECURSORS OF TYPICAL AND ATYPICAL ROASTED PEANUT FLAVOR . . 45

Introduction . . . . . . . . . . . . . . . . . . 45

Procedures . . . . . . . . . . . . . . . . . . . 45

Determination of Peanut Maturity . . . . . . . 45

Subjective Analysis of Peanut Flavor . . . . . . . 46

Preparation of Peanuts for $\mathrm{NaCl}$ or

Perchloric Acid Extraction . . . . . . . . . . . 48

Preparation of a Peanut Flavor Precursor

Fraction . . . . . . . . . . . . . . . . . . . 48

Perchloric Acid Extraction . . . . . . . . . . . 48

Preparation of Samples for Carbohydrate Analysis . 49

Gas Chromatography of Trimethylsilyl Ethers . . . 49

Amino Acid Analyses . . . . . . . . . . . . . . 50

Gross Changes in the Flavor Precursor

Fraction During Heating . . . . . . . . . . 50

Results and Discussion ............... . 50

The Effect of Heating on the Flavor

Precursor Fraction. . . . . . . . . . . . . . . 50

Changes in Individual Amino Acid

Concentration During Roasting . . . . . . . . . 52

Changes in Carbohydrates During Roasting . . . . . 61

Hypothetical Mechanism for the Conversion of

Amino Acids and Carbohydrates to Volatile

Compounds . . . . . . . . . . . . 62

V. PRODUCTION OF PRECURSORS OF TYPICAL AND ATYPICAL

PEANUT FLAVOR IN MATURING PEANUTS . . . . . . . . . . . . 65

Introduction . . . . . . . . . . . . . . . 65

Procedure . . . . . . . . . . . . . . . 65

Collection of Samples . . . . . . . . . . . 65

Extraction and Determination of Individual

Amino Acids and Carbohydrates . . . . . . . 66

Results and Discussion . . . . . . . . . . . 66

VI. FORMATION OF PYRAZINE COMPOUNDS IN MODEL SUGAR-

AMINE SYSTEMS . . . . . . . . . . . . . . . . . . . . . . 75

Introduction . . . . . . . . . . . . . . . . 75

Procedure . . . . . . . . . . . . . . . . . 76

Materials .............. . 76 
Chapter

Methods . . . . . . . . . . . . . . . . 77

Results and Discussion . . . . . . . . . . . 79

VII. SUMMARY . . . . . . . . . . . . . . . . . 93

BIBLIOGRAPHY . . . . . . . . . . . . . . . . . . 95 


\section{LIST OF TABLES}

Table

Page

I. Yield of Ultraviolet Absorbing Materials in Defatted

Peanut Cotyledons and Aleurone Grain-Protein Body

Fractions

II. Relative Retentions of Components Isolated from

Roasted Peanuts, Defatted Peanuts and the Flavor

Precursor Fraction . . . . . . . . . . . . . . . . . .

III. Sugars Found in the Flavor Precursor Fraction of

Argentine Peanuts as Determined by Gas Chromatography

of Their Trimethylsilyl Ethers . . . . . . . . . . . .

IV. Browning of Cationic Constituents of the Flavor

Precursor Fraction in the Presence and Absence

of Added Carbohydrates . . . . . . . . . . . . . . . . . . 44

V. Changes in Composition of the Flavor Precursor

Fraction During Refluxing . . . . . . . . . . . . 51

VI. Amino Acid Concentrations ( $\mu$ Moles/gram of Fat-Free Mea1) and Raw/Roasted Ratios in Fully Mature and Intermediate Maturity Peanuts . . . . . . . . . . . . 53

VII. Gas Chromatographic Analysis of Trimethylsilyl Ethers of Carbohydrates from Raw and Roasted Peanuts . . . . . 55

VIII. $K_{f}$ Values, Ratio of $K_{f}$ Values, and Average Ratios of $\mathrm{K}_{\mathrm{f}}$ Values in Intermediate Maturity and Fully Mature Peanuts... . . . . . . . . . . . . . 58

IX. $\mathrm{K}_{\mathrm{f}}$ Values and Ratio of $\mathrm{K}_{\mathrm{f}}$ Values in Immature Peanuts . . . . 60

X. Amino Acid Content ( $\mu$ Moles/gm Fat-Free Mea1) of Peanuts Classified into Three Groups According to Age Within Harvest Date . . . . . . . . . . . . . .

XI. Synthesis of Amino Acid Flavor Precursors--Amino Acid Content ( $\mu$ Moles/gm Fat-Free Mea1) of Intermediate Age Peanuts from Each Harvest Date. . . . . . . . . . . .

XII. Synthesis of Carbohydrate Flavor Precursors--Sugar

Content of Fat-Free Meal from Intermediate Age

Peanuts from Each Harvest Date . . . . . . . . . . . . 
XIII. Retention Times and Retention Times Relative to 2-Methylpyrazine of Gas Chromatographic Peaks from the Asparagine-Glucose Model System . . . . . . . .

XIV. Total Yield of Pyrazines Produced from Heated

Sugar-Amino Acid or Sugar-Ammonium Chloride

Mode1 System . . . . . . . . . . . . . . . . . . .

XV. Apparent Contribution of Various Amino Acids to

Total Pyrazines Formed During Roasting of Peanuts . . . . 91 


\section{LIST OF FIGURES}

Figure

Page

1. Elution Pattern of Dowex-1 Formate Column . . . . . . . . 35

2. MMR Spectrum of the Isolated Brown Pigment in $\mathrm{D}_{2} \mathrm{O}$. . , . . 41

3. Infrared Spectrum of the Isolated Brown Pigment on

a $\mathrm{KBr}$ Disc . . . . . . . . . . . . . . . . . . 42

4. Form Used by Each Panel Member in Organoleptic

Evaluation ................. 4 47

5. A Postulated Mechanism for the Conversion of Amino Acids and Sugars to Volatile Compounds . . . . . . . . . . . 63

6. Amino Acid Concentration in Intermediate Age Peanuts as a Function of Harvest Date . . . . . . . . . . . . . 70

7. Carbohydrate Concentration in Intermediate Age Peanuts as a Function of Harvest Date . . . . . . . . . . . . . 73

8. Distribution of Pyrazine Compounds Produced by Heating Glucose with Various Amina Acids . . . . . . . . . . . . . . 84

9. Effect of Adding Acetaldehyde to Model System Containing Glucose and Asparagine . . . . . . . . . 86

10. Distribution of Pyrazine Compounds Produced by Heating Asparagine with Various Carbohydrates . . . . . . . . . . . 88

11. Pyrazines Produced from a Mixture of Amino Acids and Reducing Sugars which are Precursors of Typical Flavor... 


\section{CHAPTER I}

\section{INTRODUCTION}

A quotation from a recent article of Lepkovsky (1) says, "An adequate diet comprises the essential nutrients plus sensory stimuli with sensory properties being treated collectively as an essential nutrient." Indeed sensory depreivation may lead to peurosis and psychosis. Flavors of food may become an important source of sensory stimuli (2).

Flavor is a nebulous term the definition of which no two authors agree upon completely. The presently accepted definition of flavor which was advanced by Moncrieff (3) includes the sensations of taste (sweet, sour, bitter, and salty), odor (via olfactory receptors), tactual response (via pain receptors), hotness or coldness, and pungency or blandness. Of these qualities, odor and taste are the main contributors to flavor. Yet if one's sense of smell is deadened, most of the flavor disappears. Taste remains but, without odor, an apple and an onion taste alike, Few foods have a characteristic flavor which can be described by ane of the basic taste responses alone. In order for a chemical compound to play a significant role as a food aroma, it is evident that it must have significant volatility since without a reasonably high vapor pressure a compound is unable to reach the locus of the odor response. Much of the modern work in the chemistry of flavor is based upon this reasoning. In other words, it is assumed that the odor of a food product rather than its taste or feel actually defines the typical 
flavor of that food.

If this reasoning is valid, then it should be possible to reproduce a flavor by adding compounds which elicit the odor response of a given food to a medium having the correct tactual and taste response. That this is in fact possible has been shown by recent work on the production of artificial pork from soybean meal. If the typical pork flavor compounds are added to or produced in this high protein (therefore meatlike) medium, the product is nearly indistinguishable from natural pork (4).

Several foods such as peanuts, cocoa beans, and coffee require a process in which they are roasted at high temperature to induce chemical reactions which in turn produce volatile compounds which give the roasted product its typical flavor. Since peanuts are such a pyrrolytically processed food product, they represent an excellent system in which to study the compounds of low volatility which are converted to more volatile ones during heating and the manner in which this conversion takes place.

A study of the flavor precursors of peanuts was initiated for the following reasons:

1) Most importantly, to accumulate basic knowledge concerning the kinds of compounds that serve as flavor precursors in foods.

2) To determine if there exists a correlation between flavor measured subjectively and flavor precursor concentration. If such a correlation could be demonstrated, it would be possible to predict the flavor of a roasted peanut product by means of a few objective measurements made on raw peanuts.

3) Knowledge of the flavor precursors will allow one to take a scientific approach to the off-flavor problem which arises from either 
improperly cured or very immature peanuts. Even correctly cured immature peanuts possess a high degree of off-flavor. This fact means that immature peanuts either contain high concentrations of flavor precursors which are converted to compounds associated with atypical flavor during roasting or that they lack precursors of typical flavor. Therefore it becomes important to study the formation of peanut flavor precursors as a function of growing season to determine if a correlation exists between flavor precursor concentration and age of the peanut fruit.

The objectives of the work reported in this thesis were fourfold:

1) To develop methods of extraction and quantitative estimation of peanut flavor precursors.

2) To determine the nature and identity of the precursors of typical peanut flavor.

3) To quantitatively measure peanut flavor precursor concentration with respect to flavor measured subjectively and peanut age.

4) To investigate pyrrolytic reactions of the flavor precursors in model systems to determine:

a) If the so-called flavor precursors when heated can give rise to the same volatile compounds which have been isolated from normally roasted peanuts.

b) The likely mechanism(s) of formation of these volatile flavor components in peanut-1ike model systems. 
CHAPTER II

\section{LITERATURE REVIEW}

\section{Introduction}

With the exception of sweetness, raw peanuts exhibit none of the flavor usually associated with roasted peanut products such as peanut butter. Since this is the case, it is obvious that raw peanuts contain compounds (flavor precursors) which are converted to new compounds (flavor components) which give roasted peanuts their characteristic flavor.

Roasting of peanuts represents an unusual system in that the internal temperature of the peanut cotyledon reaches $130-150^{\circ} \mathrm{C}$ during the process (5). The internal temperature of food products such as meat and vegetables seldom reach temperatures greater than $100^{\circ} \mathrm{C}$ since they have a very high initial and final water content. Peanuts and other food products such as coffee and cocoa which have low moisture content therefore represent a system in which to study the chemical reactions which can occur between the constituents of the food at higher temperatures. The nature of these pyrrolytic reactions and their reactants are of extreme interest collectively since they must dictate the nature of the products produced which in turn determine the flavor of the finished product.

A knowledge of the exact mechanisms of production of flavor in such pyrrolytically processed foods would allow the duplication of a natural 
flavor in an artificial system or the modification of the flavor of a natural food product.

In this review, the author will discuss what was known concerning the precursors of peanut flavor prior to the work described in this dissertation. Research on flavor precursors of other pyrrolytically processed foods, especially cocoa, will be discussed along with a review of the relationship between the Maillard browning reaction and production of volatile flavor components.

\section{Precursors of Peanut Flavor}

In 1952, Pickett and Holley (5), of the University of Georgia, published a bulletin, later reviewed by Hoffpauir (6), which contained a summary of their studies on the process of peanut roasting. A significant portion of this work was concerned with the changes in concentration of various compounds (possible flavor precursors) during roasting. Their investigation will be discussed in some detail since it represented the state of knowledge up to 1964 when a study of peanut flavor precursors was initiated by Mason and Waller (7).

Pickett and Holley noted prior to 1952 that during roasting peanut proteins were denatured ( 8 ) but that their nutritive value was unchanged (9). The oil and starch remained unchanged (8), while total sugars decreased.

Volatile components associated with the gases over roasted peanuts were found to consist of 98 percent of carbon dioxide and lesser quantities of aldehydes, furfurals, ammonia, hydrogen sulfide, diacetyl and volatile sulfur compounds. These workers (5) concerned themselves with determining the origin of these volatile substances.

It was found that peanut protein heated at $150^{\circ} \mathrm{C}$ gave hydrogen 
sulfide but no carbon dioxide. A 50 percent acetone extract of raw peanuts when dried and roasted, browned and evolved hydrogen sulfide and carbon dioxide. By fractionation of the acetone extract it was found that browning and carbon dioxide evolution arose from nonenzymatic browning reactions between amino acids and water soluble carbohydrates. After it was established that the Maillard reaction (nonenzymatic browning reaction between amines and carbohydrates) was important in peanut roasting, total free amino nitrogen was measured during the course of an ordinary roast and was found to decrease significantly. However it was shown that total nitrogen did not decrease significantly. Sucrose concentration decreased when peanuts were heated for prolonged periods of time (5) .

These authors went on to study the Maillard reaction between sucrose and amino acids in aqueous solutions at normal roasting temperatures. Alanine and sucrose when heated together in aqueous solution browned and produced carbon dioxide; in the dry state no browning or carbon dioxide evolution was observed. During the reaction, production of unfermentable reducing substances was noted. It was concluded that either sucrose was not hydrolyzed prior to its participation in browning or that the hydrolysis products were immediately consumed by the amino acid in the system since using their methods, no glucose or fructose could be detected during the course of the reaction.

A number of amino acids including aspartic acid, asparagine, glutamic acid, serine, glycine, threonine, alanine, alpha amino-n-butyric acid, histidine, arginine, lysine, methionine, leucine or isoleucine, phenylalanine, tyrosine and tryptophan were detected on paper chromatograms of 70 percent ethanol extracts of raw peanuts. Cystine, proline, 
glutamine and glucosamine were tentitively identified. Extracts of roasted peanuts contained the same amino acids but at lower concentrations than in the raw nuts. Pickett and Holley also demonstrated that of the isomeric alanines, only alpha alanine produced carbon dioxide when heated with sucrose at $140^{\circ} \mathrm{C}$; either alpha- or beta-alanine gave brown products (5). From this evidence it was proposed that browning during roasting of peanuts might arise via three routes: from carame1ization, Maillard reaction or reaction of carbohydrates with free nonterminal amino groups in protein.

Raw peanuts were soaked in solutions of amino acids and reducing sugars and after drying it was observed that a normal roast could be obtained at a much lower temperature while the color and aroma of the nuts were nearly normal (5).

The work of Pickett and Holley (5), while limited by the experimental tools available in 1952 , is consistent with results to be discussed in this thesis. One criticism of their work is that a decrease in amino acid and carbohydrate concentration during roasting was only circumstantial proof that these compounds were flavor precursors. Flavor precursors must be shown to be reactants in the processes which produce volatile flavor components. However at the time of Pickett and Holley's work the flavor components of peanuts were largely unknown since modern methods were not available for the identification of trace amounts of volatile compounds. Since the Georgia workers demonstrated that amino acids and sucrose could give rise to Maillard browning and since browning might serve as a marker of formation of flavor components (7), the observed browning could be taken as somewhat better than circumstantial evidence that the reactants were indeed flavor precursors. 
Another criticism is that these workers used aqueous model systems. Since peanuts contain only 4-6 percent water (5) the aqueous system is not a valid model for roasting peanuts.

Nothing concerning peanut flavor precursors appeared until 1964 when Mason and Waller (7) from this laboratory published a paper concerning the isolation and localization of the precursors of roasted peanut flavor. Ground defatted peanuts which characteristically contain large amounts of globular protein were stirred with $1 \mathrm{M}$ sodium chloride. After removal of the insoluble material by centrifugation the soluble material ( 45 percent of the original dry weight of the fat-free peanuts) was lyophilized to dryness and roasted. Since the roasted material had the aroma of roasted peanuts it was evident that flavor precursors were contained in this fraction. The components of the unheated soluble extract were separated by gel filtration on Sephadex G-25. Each individual peak from this column was lyophilized and roasted. Only the fraction (the flavor precursor fraction) which contained molecules of low molecular weight gave rise to peanut aroma upon heating. The very large amount of protein isolated produced little or no aroma or browning upon heating in the dry state. Paper chromatography of the flavor precursor fraction indicated the presence of two ninhydrin positive components and one spot which was highly basic and exhibited a yellow ninhydrin reaction.

Linear Arrhenius type plots of the $\log$ of the time required to roast a series of peanut samples plotted versus reciprocal temperature of roasting were interpreted to mean that the rate limiting processes occurring during peanut roasting were unimolecular decompositions. This could have meant that production of flavor resulted from decomposition 
of a single preformed flavor precursor although this mechanism seems unlikely in view of results to be discussed in this thesis.

Mason and Waller (7) also found that a single subcellular fraction of raw peanuts, the aleurone grain-protein body fraction, produced typical peanut flavor when roasted; starch grains or vascular material exhibited little typical roasted peanut aroma upon heating.

The work of Mason and Waller (7) does not completely rule out the possibility that protein could be a precursor of peanut flavor since it was not heated with a carbohydrate which was indicated to be a necessary reactant in the reactions to produce flavor by the work of Pickett and Holley (5). During roasting of coffee protein bound arginine was extensively degraded, cystine, lysine, serine and threonine were slightly degraded while other protein amino acids remained unchanged during roasting (10).

\section{Peanut Flavor Components}

Any mechanism to explain the decomposition of flavor precursors must take into account the volatile flavor components produced during the reactions involving the precursors.

As previously mentioned, Pickett and Holley (5) demonstrated the presence of carbon dioxide, aldehydes, ammonia and sulfur compounds. More recently Pattee et al. (11) found by means of gas liquid chromatographic retention times and functional group tests, formaldehyde, acetaldehyde, ethanol, acetone, isobuteraldehyde, 2-methyl valeraldehyde, methy1 buty1 ketone, hexaldehyde, 2-or 3-methy1 butanol (tentatively) and furfural in raw, high temperature cured, off-łlavored peanuts. Recently Young and Holley (12) showed that roasted off-flavored peanuts contained unusually large amounts of volatile carbonyl compounds. 
Mason et al. (13) characterized by nuclear magnetic resonance spectrometry, ultraviolet spectroscopy and mass spectrometry 2-methylpyrazine, 2,5-dime thylpyrazine, trime thylpyrazine, 2-me thy 1-5-ethylpyrazine, 2,5dimethy $1-3-e t h y l$ pyrazine and $N$-methylpyrrole from peanuts having normal flavor. In a later paper, the same group (14) identified acetaldehyde, isobuteraldehyde, benzaldehyde, phenylacetaldehyde and tentatively 2and 3-methylbutanals and 3-methy1-2-butanone by use of gas liquid chroma-tography in conjunction with a rapid scanning mass spectrometer, thin 1 ayer chromatography of 2,4-dinitrophenylhydrazone derivatives along with ultraviolet spectra and regeneration of the derivatives (15). Mason (14) believed that phenylacetaldehyde contributed to the sweet bouquet of roasted peanuts; low molecular weight aldehydes gave the harsh note to freshly roasted peanuts. Pyrazines were apparently the compounds responsible for the roasted-nutty aroma of peanuts (13). However Deck and Chang (16) reported aroma responses of "earthy-raw potato" for 2,5-dimethylpyrazine.

From this flavor component work taken as a whole, one might conclude that pyrazine compounds give peanuts their nut-like aroma while aldehydes play a contributory role. Aldehydes in high concentrations might be responsible for atypical-or off-flavor.

\section{Precursors of Chocolate Aroma}

Cocoa beans, like peanuts, require roasting to develop their typical flavor. Rohan (17) found that cocoa flavor precursors were water soluble, methanol soluble, dialyzable compounds. The flavor precursor fraction of fermented cocoa beans was composed of 35 percent sugars, 25 percent amino acids and 30 percent flavonoids. These extracted precursors, which accounted for 5 percent of the shel1-free bean, produced 
typical chocolate aroma upon heating for 8 minutes at $130^{\circ} \mathrm{C}$. This observation held in fermented beans but not in unfermented ones (18). The main groups of compounds in the cocoa flavor precursor fraction were separated into flavonoids, amino acids and carbohydrates by lead acetate precipitation and cation exchange chromatography (18). Fermented beans contained lower concentrations of carbohydrates and higher concentrations of amino acids than unfermented ones. Unfermented beans contained only sucrose while fermented ones contained glucose and fructose in addition. Al1 amino acids except histidine increased in concentration during fermentation. The flavonoids and phenolic acids contained in the flavor precursor fraction of cocoa did not appear to be essential to production of chocolate aroma (19).

Later the same group (20) showed that different varities of cocoa had different amino acid concentrations and it was postulated that the differences in flavor between varieties arose from the variability in amino acid levels in the fermented bean.

Rohan and Stewart (21) determined the concentration of groups of amino acids during roasting of Accra cocoa beans at $182^{\circ} \mathrm{C}$. The results indicated that destruction of amino acids was a linear function of time of roasting and that only about 50 percent of the total amino acids were destroyed during the course of an ordinary 28 minute roast. Different groups of amino acids reacted at variable rates. Total nitrogen in the beans was unaltered during roasting just as was observed in the case of peanuts (5). A mechanism employing the ideas of Schonberg et al. (22, 23) concerning the mechanism of Strecker degradation, was proposed to explain the decrease in amino acid concentration during roasting of cocoa beans. 
In some particularly elegant work, Pinto and Chichester (24) determined individual amino acids and total reducing sugars utilized during roasting of cocoa. In addition, they followed the production of individual aldehydes by gas-liquid chromatography. They found that all amino acids were destroyed during roasting with the exception of methionine and that glutamic acid, leucine, phenylalanine and an unknown amino acid decreased markedly in concentration. Ammonia increased during roasting (a phenomenon noted during roasting of peanuts--Chapter IV). A very large increase in concentration of isovaleraldehyde was noted along with smaller increases in concentration of propionaldehyde and isobutyraldehyde. Volatile aldehydes identified in addition to those already mentioned were acetaldehyde and diacetyl. It was interesting to note that the concentration of acetaldehyde initially increased and then decreased during the final stages of roasting. The significance of this observation was not discussed.

Both Pinto and Chichester (24) and Rohan and Stewart (25) found nearly complete destruction of reducing sugars during cocoa roasting. Further, Rohan and Stewart's results (25) suggested destruction of sucrose during roasting presumably by hydrolysis to glucose and fructose. They explained the incomplete destruction of amino acids during roasting by the fact that the degrading reagents, reducing sugars, were completely utilized during the process (25).

The overall conclusion was that amino acids were converted to aldehydes by Strecker degradation which occurred during roasting. The evidence of Pinto and Chichester (24) concerning the origin of volatile flavor components seems to be irrefutable since a large decrease in leucine concentration and a concomitant increase in its strecker aldehyde, 
isovaleraldehyde, was demonstrated. This evidence is all the more convincing since Herz and Shallenberger (26) produced chocolate aroma by heating leucine, glutamine and threonine at $100^{\circ} \mathrm{C}$ and valine at $180^{\circ} \mathrm{C}$ with glucose.

Considering the striking morphological similarities of peanuts and cocoa beans (27) and the similarity of the roasting process to which each is subjected, it is not surprising that these two foods have the same flavor precursors (amino acids and carbohydrates). It is surprising that simple alkylated pyrazines have not been isolated from roasted cocoa beans since they have been characterized in peanuts (13), coffee $(28,29)$ and heated carbohydrate-amino acid model systems (30, Chapter VI). This author suggests that pyrazine compounds will prove to be quantitatively important in the volatile components of roasted cocoa beans. However it is impossible to predict the significance of pyrazines in the flavor of chocolate.

\section{Chemistry of Nonenzymatic Browning}

Evidently, considering what has previously been discussed, one of the primary events occurring during roasting of peanuts or cocoa beans is the Maillard reaction between amino acids and reducing carbohydrates. Since this is true, a brief description of the reactions occurring during the Maillard reaction, taken from the volumes of literature available on this reaction, is in order since a mechanism based upon the Maillard reaction is proposed in this thesis to account for the formation of flavor compounds during roasting of peanuts.

The Maillard reaction is very complex and, as a result, most of the knowledge concerning the reaction has been derived from work in simplified model systems which contain a single amino acid and carbohydrate. 
Information concerning the chemistry of nonenzymatic browning reactions was reviewed by Heyns and Paulsen (31), Danehy and Pigman (32), Reynolds $(33,34)$, Ellis (35), Anet (36) and Hodge (37). The very detailed reviews of Reynolds $(33,34)$ are an excellent guide for those interested in the preparation and properties of intermediates in the Maillard reaction; the review of Hodge (37) is concerned with the chemistry of browning from the standpoint of the food or flavor chemist. Hodge's review (37) presents the Maillard reaction in an extremely well organized manner and was used as an outline for the review presented here. Hodge (37) divided the browning reaction into three stages. The initial colorless stage involves sugar-amine condensation and Amadori rearrangement. In the intermediate (colorless or yellow) stage, sugar dehydration, sugar fragmentation and amino acid degradation occur. In the highly colored final stages, aldol condensation, aldehyde-amine polymerization and formation of heterocyclic nitrogen compounds occurs.

\section{Initial Stage--Sugar Amine Condenșation}

The initial stages of the Maillard reaction between glucose and glycine have recently been investigated by Song and Chichester (38) and Song et a1. (39). Song et a1. (39) studied the kinetics of formation of brown polymers during the Maillard reaction and observed a pronounced lag phase prior to the steady phase formation of melanoidins (brown polymeric materials). The lag phase was interpreted to mean that certain colorless intermediates were formed prior to the steady phase formation of melanoidins. They prepared N-D-glucosylglycine and compared ịts chromatographic properties with a product from a heated aqueous glucoseglycine model system (38)...The coincidence of the synethtic material with the compound from the model system was interpreted to mean that 
N-D-glucosylglycine was one of the primary products formed in this Maillard reaction. Qualitative tests on the isolated material also indicated that it was N-D-glucosylglycine. That the material from the model system was composed of glucose and glycine was shown by the fact that it incorporated label from either ${ }^{24} \mathrm{C}$ glucose or ${ }^{14} \mathrm{C}$ glycine to the same extent.

Song and Chichester (38) determined the induction period for a number of different sugar-amino acid reactions. A short induction period meant that the rate of reaction for one of the components was faster than in the glucose-glycine system. In other words, a short induction time meant that a rate limiting reaction had been overcome. A fructoseglycine mixture had an induction time of $2.3 \times 10^{3}$ minutes while the glucose-glycine system had an induction period of $6.9 \times 10^{3}$ minutes. This observation was explained by the increased reactivity of the carbonyl group of fructose toward nucleophylic attack by glycine. In comparison, $\alpha$-methyl-D-glucoside which has a stable hemiacetal ring had an induction time of $13 \times 10^{3}$ minutes while arabinose which possesses an unstable hemiacetal had an induction time of only, $1.1 \times 10^{3}$ minutes. On the basis of this evidence, the open chain form of glucose was judged the reactive species of the carbohydrate in the Maillard reaction. As the $\mathrm{pH}$ of the reaction mixture approached $\mathrm{pk}_{\mathrm{z}}$ of glycine, the velocity of browning increased markedly. Thus the conjugate base of the glycine amino group, rather than the conjugate acid, must have been the reactive species of the amino acid. On the basis of Song and Chichester's evidence (38) nucleophylic attack of the conjugate base of the glycine amino group on the carbonyl group of glucose in its open chain form was the primary event in the Maillard reaction. 
Initial Stage--Reaction of $\mathrm{N}$-Substituted Carbohydrate

Song and Chichester (38) detected another compound in their work with the glucose-glycine system which contained glucose and glycine in equimolar quantities. They felt that it was formed by consecutive reac-

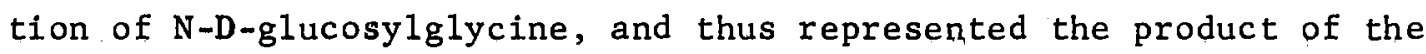
second step of the Maillard reaction. The fact that the compound gave a positive test with $\mathrm{m}$-phenylenediamine and decolorized bromine indicated to them that the compound was probably an $\alpha, \beta$-unsaturated enolic aldimine in equilibrium with its keto form. This unsaturated compound was isolated from the glucose-glycine reaction mixture by adsorption onto aluminum oxide. When the material, which had an ultraviolet spectrum characteristic of a semicarbazone, was eluted from the adsorbant with ether, it browned rapidly at room temperature. This fact substantiates the conclusion that the unsaturated compound was indeed an intermediate in the browning reaction.

2-propenal was used as a model of a compound having a structure more like the postulated $\alpha, \beta$-unsaturated aldimine intermediate and it was found that the 2-propenal-glycine model system had no induction period. The induction period when 2-amino-D-glucose was heated alone at pH 6.0 was 150 times less than in the glucose-glycine system. These induction time data point to the fact that during the induction period in the glucose-glycine reaction nitrogen was incorporated into the carbohydrate and unsaturation was produced. In the kinetic studies of Katchalsky and Sharon (40), the formation of the N-D-glucosylamino acid was assumed to be the rate determining step in the Maillard reaction. The work of Song and Chichester (38) and Song et al. (39) bears out this assumption since substitution of a substrate which was more reactive to 
nucleophylic attack by the amino acid amino group exhibited a reduced induction period $(38,39)$.

Because they isolated a reactive $\alpha, \beta$-unsaturated aldimine, Song and

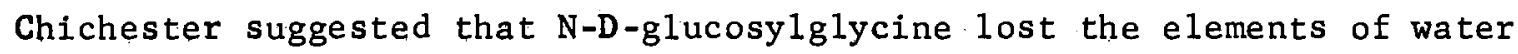
to give the Amadori rearrangement product keto, 1-amino-1-deoxy-glycinoD-fructose in equilibrium with its enol. This enol lost water at C-3 to yield the $\alpha, \beta$-unsaturated aldimine. Hodge (37) pointed out that Amadori rearrangement (conversion of $\mathrm{N}$-substituted aldosylamines to 1-amino1-deoxy-2-ketoses) was suspected to occur during the Maillard reaction, but it was not until 1952 that the Amadori product was isolated by Hodge (41) and Gottschalk (42). That the Amadori product was an intermediate in nonenzymatic browning was demonstrated by the fact that the $N$ substituted glucosylamine browned at room temperature and from the browned material could be isolated the Amadori rearrangement product in 30-50 percent yield. However, if the C-2 hydroxyl of the $\mathrm{N}$-substituted glucosylamine was substituted (2-0-methyl-D-glycosylpiperidine) then the derivative remained white and stable for over two years at $25^{\circ} \mathrm{C}(41,43)$. The carbohydrate which participated in the formation of the N-substituted glucosylamine could not be isolated after acid hydrolysis of the Amadori product (44). This is an indication that reactions occurred within the carbohydrate moiety of the glucosylamine during the Amadori rearrangement.

Other workers proposed that furans play an important role as intermediates in the Maillard reaction $(35,45)$. However, Song and Chichester (38) showed that addition of hydroxymethyl furfural (HMF) did not eliminate the induction period in the browning reaction. It was reasoned that if HMF were an intermediate it would reach its maximum concentration 
near the end of the lag phase of the reaction, however the experimental evidence indicated that HMF was accumulated throughout the reaction rather than incorporated into the steady phase of the reaction. Also these authors pointed out that trioses and tetroses could undergo browning but could not form HMF. From the data and these lines of reasoning, HMF was concluded not to be an important intermediate in Maillard browning.

Intermediate Stage of Browning--Dehydration of Sugar Moiety

The intermediate stage of the Maillard reaction is characterized by appearance of absorbancy in the region from 277-285 mu. Dehydration of the sugar by loss of the elements of three molecules of water and cyclyzation gives a furfural. As was mentioned earlier, furfurals are not important intermediates in browning (39). Hodge and Rist (43) showed that after Amadori rearrangement the sugar moiety can lose two molecules

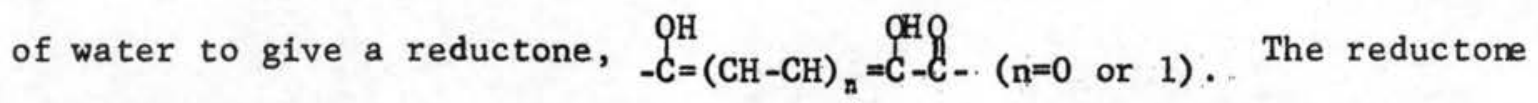
browned in aqueous solution at $\mathrm{pH} 6.0$, more rapidly in the presence of an amino acid. The reductone described by Hodge and Rist is very similar to the dehydration product postulated to arise from the $\alpha, \beta-$ unsaturated aldimine by Song and Chichester (38).

Thus in the dehydration stage of the Maillard reaction, two primary events apparently occur: loss of three molecules of water to give furfurals or loss of two molecules of water from the carbohydrate moiety to give a reductone or a reductone-like product containing nitrogen in the case of dehydration of an $\alpha, \beta$-unsaturated aldimine.

Intermediate Stage of Browning--Fragmentation of Sugar Moiety Among the known sugar fission products are glycolaldehyde, 
glyceraldehyde, pyruvaldehyde, dihydroxyacetone, acetoin, diacetyl, acetaldehyde, aldol, triose reductone and propionaldehyde $(37,46)$. Many of these compounds, especially with the $\alpha$-hydroxycarbonyl grouping, can undergo browning and many have characteristic aromas which could be of importance in the flavor of heated foods which contain carbohydrates. The accepted mechanism for sugar fragmentation according to Hodge (37) is a reverse aldol condensation (dealdolization). Since the aldol condensation is catalyzed by amines and their salts, these same reagents will also catalyze the reverse reaction. The dealdolization of diacetone alcohol was catalyzed by amines but not bases in general (47). To explain dealdolization, Hodge (37) postulated that the 1,2-enol or 2ketose configuration of the Amadori rearrangement product had a weakened $\mathrm{C}-\mathrm{C}$ bond $\alpha, \beta$ to the carbonyl group.

Intermediate Stage of Maillard Browning--Strecker Degradation

Strecker degradation is the conversion of $\alpha$-amino acids to aldehydes containing one less carbon atom (Strecker aldehydes) and carbon dioxide. The importance of this reaction to the formation of flavor components (e.g. 3-methylbutanal from leucine during roasting of cocoa beans and phenylacetaldehyde from phenylalanine during peanut roasting) has already been noted in this literature review. Strecker degradation was reviewed by Schonberg and Moubasher (22) and Schonberg et a1. (23). It was found that only carbonyl compounds containing the structure C $-(-C=C-)_{n}-C-(n=0,1,2 \ldots)$ are capable of initiating Strecker degradation. It can be seen that the type of molecule reactive in Strecker degradation could be formed by dehydrogenation of a reductone $\left(-\mathrm{OH}=(\mathrm{CH}-\mathrm{CH})_{n}=\mathrm{CH}-\mathrm{C}-\right)$ formed during the Maillard reaction. Transamination of the amino group of the amino acid to the degrading molecule could be important in the 
incorporation of nitrogen into Melanoidin pigments. The fact that little ammonia is released during Strecker degradation has been demonstrated (48).

Stadtman et al. (49) have shown by the use of ${ }^{14} \mathrm{C}$ labelled glucose and glycine that over 80 percent of the carbon dioxide generated during Strecker degradation arises from the amino acid carboxyl group; ten percent arises from glucose. The fact that Maillard browning, carbon dioxide production and production of Strecker aldehydes are nearly paralle1 reactions has been pointed out (37). The aldehydes produced during Strecker degradation, especially acetaldehyde, can undergo browning in the presence of amino acids (50). However, this process is probably of little importance as a color producing reaction.

In summary, the intermediate stage of Maillard browning is characterized by dehydration reactions to give furfurals and/or reductones, production of sugar degradation products, and Strecker degradation.

\section{The Final Stages of Browning}

In the final stages of browning, the compounds formed during the intermediate stage are thought to polymerize to unsaturated, colored, nitrogen containing polymers. The chief reactions, on the basis of inhibition studies, were aldol condensations, aldehyde-amine polymerization and formation of heterocyclic nitrogen compounds such as pyrazines, pyrroles, pyridines and imidazoles (37). Song and Chichester (38) postulated that anionic polymerization occurred by nucleophylic attack of electrons from highly unsaturated nitrogen containing carbohydratelike molecules on carbonyl groups. The structure of their proposed intermediates is in accord with the evidence of other workers who found that the backbone of the brown pigments apparently corresponded to 
carbohydrates less three molecules of water (51). U1traviolet spectra of the brown polymers from a glucose-glycine model system appeared to be due to $\pi \rightarrow \pi^{*}$ transitions as was predicted for the postulated polymeric materials.

Flavor Components Produced by Sugar-Amine Reactions

Certain volatile compounds that might be important to flavor are produced during the Maillard reaction. That this is the case has already been discussed in this review in connection with production of flavor components during roasting of cocoa beans or peanuts.

As has previously been pointed out, many of these compounds originate by Strecker degradation of $\alpha$-amino acids or sugar fragmentation during the Maillard reaction.

The formation of volatile pyrazine compounds during roasting of peanuts and coffee has been discussed previously but nothing was mentioned concerning the origin of this class of compounds.

Only scattered reports concerning formation of pyrazines during the Maillard reaction are available. Etard (52) and Stoehr (53) demonstrated formation of 2,5-dimethylpyrazine and traces of 2,5-dimethy1-3ethylpyrazine by distillation of glycerol with a mixture of ammonium chloride and ammonium phosphate. Formation of acrolein from glycerol with concomitant combination of two molecules of ammonia was the mechanism postulated to explain the formation of the dimethyl derivative. Stoehr (54) observed that addition of acetaldehyde increased the yield of 2,5-dimethyl-3-ethylpyrazine in this reaction. Other workers $(55,56$, 57) detected pyrazine, 2-methylpyrazine and 2,6-dimethylpyrazine when glucose and ammonium hydroxide were heated at $100^{\circ} \mathrm{C}$. Wiggins (58) treated inverted molasses for two hours at $100-120^{\circ} \mathrm{C}$ with anhydrous 
ammonia at 60 pounds per square inch. From the reaction mixture were isolated a number of imidazole compounds ( $10 \%$ yield) and pyrazine derivatives (20\% yield) which included 2,6-dimethylpyrazine, 2-hydroxymethylpyrazine, 5-hydroxymethy1-2-methylpyrazine, 2-methy1-5-arabotetrahydroxybutylpyrazine and 2-methy1-6-arabotetrahydroxybutylpyrazine. Stiles (59) found that acid or invertase treated molasses incorporated nearly twice as much ammonia as did non-inverted molasses. This information pointed out the importance of monosaccharides to the formation of pyrazine compounds. Hough et al. (60) reacted glucose and aqueous ammonia at $37^{\circ} \mathrm{C}$ for two weeks and isolated 2-methy1-5-(tetrahydroxybutyl) pyrazine and 2-methy1-6-(tetrahydroxybuty1) pyrazine. These derivatives were found to occur in the D-arabo configuration based upon molecular rotation evidence. Reaction of glucose or fructose with alcoholic ammonia yielded fructoazine (2,5-bistetrahydroxybutylpyrazine). $(61,62)$.

The mechanism of formation of simple volatile alkyl pyrazines is at present unknown. In a recently published paper, Dawes and Edwards (30) identified 2,5-dimethylpyrazine and trimethylpyrazine from aqueous aldose-amino acid solutions refluxed for two hours at $\mathrm{pH} 9.0$. 2,5dimethylpyrazine was isolated from both L-phenylalanine-D-fructose and glycine-D-fructose model systems; trimethylpyrazine was formed only in the glycine system. The formation of these compounds was explained in the following manner: Pyruvaldehyde was assumed to be generated by degradation of the carbohydrate. Amino acetone or 2-amino-propanal was postulated to be formed from the reaction of the amino acid and pyruvaldehyde. Condensation of these $\alpha$-amino carbonyl compounds was postulated to occur to give a dihydropyrazine which underwent oxidation to 2,5-dimethylpyrazine. In like manner, trimethylpyrazine was assumed to 
arise by condensation of 2 -amino-propanal or amino acetone with the $\alpha$ amino ketone derived from diacetyl. The suggested mechanism is attractive since Hurd (63) demonstrated the formation of 2,5-dimethylpyrazine from a model system containing acetol and alanine. It is possible that simple alkyl substituted pyrazines could arise from the easily formed fructosazine by removal of portions of the tetrahydroxybutyl side chains. However this kind of reaction is difficult to rationalize; the former one is simple to rationalize in terms of known reactions of Maillard browning. 
CHAPTER III

\section{SOME PROPERTIES OF THE FLAVOR PRECURSOR FRACTION}

OF SPANISH PEANUTS

\section{Introduction}

Mason and Waller (7) described the isolation of a soluble fraction of raw peanuts which produced typical peanut aroma when heated in the dry state, This soluble fraction was called the flavor precursor fraction. Since the flavor precursor fraction evidently contained all of the compounds necessary to produce peanut aroma during heating, the nature of the compounds in this fraction was of great interest.

Work described in this chapter was aimed at the qualitative determination of the nature of the components in the flavor precursor fraction, the nature of the brown pigment formed when the flavor precursor fraction was heated and a comparison of volatile compounds formed when the flavor precursor fraction was heated with the volatile compounds isolated from normally roasted peanuts and heated defatted peanut meal.

\section{Reagents}

Ion retardation resin AG-11A8 (50-100 mesh) and Aminex-MS cation exchange resin (blend Q-50) were purchased from the Biorad Corporation, Richmond, California; Sephadex G-25 (course grade) was purchased from the Pharmacia Chemical Company, Uppsala, Sweden. Apiezon-L, SE-52, and the Chromosorb W (60-80 mesh) were obtained from the Wilkins Instrument Company, Walnut Creek, California. Hexamethyldisilazane and 
trimethylchlorosilane we re purchased from Applied Science Laboratories, Inc., State College, Pennsylvania. Elemental analyses were performed by Midwest Microlab, Inc., Indianapolis, Indiana.

\section{Procedure*}

Preparation of the Flavor Precursor Fraction

Ten pounds of raw peanuts with hearts and testa removed were ground with a food grinder and defatted by soxhlet extraction with redistilled n-hexane for 48 hours. After removal of the hexane by evaporation at room temperature, the fat-free material was homogenized at one-half speed with 1M NaCl solution ( 7.5 liters per $\mathrm{kg}$ of fat free meal) in a Servall Omnimixer for 2 minutes. The resulting suspension was stirred in a plastic bucket for 24 hours at $5^{\circ} \mathrm{C}$. The insoluble peanut meal was allowed to settle and the supernatent suspension was centrifuged for 15 minutes at $5000 \times \mathrm{g}$. The clear supernatent solutions from the centrifuge bottles were combined and the extract was reduced to 1 1iter by rotary evaporation. All of the evaporated material was placed on a Sephadex G-25 column $(10.2 \times 132 \mathrm{~cm})$. The column was developed with $1 \mathrm{M}$ NaCl solution at a flow rate of $35 \mathrm{ml}$ per min; $100 \mathrm{ml}$ fractions were collected. The peaks corresponding to the flavor precursor fraction (fractions 65-115) described by Mason and Waller (7) were collected. The flavor precursor fraction contained $0.43 \mathrm{gm}$ per $\mathrm{m} 1$ of total organic solids as determined by the procedure of Johnson (64).

A portion of the flavor precursor fraction was placed on a $4.9 \mathrm{x}$ $36 \mathrm{~cm}$ column of Biorad AG-11A8 ion retardation resin. The column was developed with deionized water at a flow rate of $10 \mathrm{ml}$ per minute. The

*Abbreviations used throughout this dissertation are those suggested in the Journal of Biological Chemistry 242, 1 (1967). 
salt free fractions were combined; fractions containing both organic material and $\mathrm{NaCl}$ were combined, evaporated to $70 \mathrm{ml}$, and recycled. This procedure gave a salt free preparation suitable for qualitative analysis.

Comparison of the Yield of Various U1traviolet Absorbing Fractions from Whole Peanut Cotyledons and Peanut Aleurone Grain-Protein Body Fractions

Fifty gram samples of the aleurone grain-protein body fraction of peanuts prepared as described by Mason and Waller (7) and defatted peanut cotyledons were extracted with $1 \mathrm{M} \mathrm{NaCl}$ solution as described in the section entitled "Preparation of the Flavor Precursor Fraction." Sephadex gel filtration curves were prepared in the manner shown by Mason and Waller (7) for extracts of peanuts and the aleurone grain-protein body fraction.

The absorbancy of each peak in the elution pattern at its absorption maximum and the width of each peak in $\mathrm{ml}$ was determined from the elution pattern. The product of the peak height and peak width represented the amount of ultraviolet abșorbing material (in arbitrary units) in that peak.

Determination of Neutral Amino Acids in the Flavor Precursor Fraction

Neutral amino acids in the flavor precursor fraction were determined qualitatively using procedures similar to those outlined by Hunter et a1. (65) in which aldehydes having one less carbon atom than their parent amino acids were prepared by the use of the ninhydrin reaction.

Two hundred $\mathrm{mg}$ of ninhydrin and $100 \mathrm{mg}$ of a mixture containing $19.15 \mathrm{gm}$ of citric acid and $2.06 \mathrm{gm}$ of tripotassium citrate were mixed with $5 \mathrm{ml}$ of flavor precursor fraction in saturated NaCl solution which 
was obtained by evaporation of the fraction collected from the Sephadex G-25 column. After refluxing the mixture for $30 \mathrm{~min}$, it was steam distilled until $10 \mathrm{ml}$ of distillate were collected. Aldehydes present in the distillates were determined in the manner to be described in the section entitled "Gas Chromatography." Standard amino acids were treated in the same manner and served as standards for the identification of amino acids present in the flavor precursor fraction.

A11 neutral amino acids except tryptophan, proline, hydroxyproline, and cystine could be detected in artificial mixtures using this procedure.

Separation of Anionic Constituents of the Flavor Precursor Fraction

A $30 \mathrm{ml}$ portion of the desalted flavor precursor fraction was placed on a $0.9 \times 45 \mathrm{~cm}$ column of Dowex 1 in the formate form. A gradient elution, similar to that described by Wilken and Hansen (66), in which the eluant was delivered to a $500 \mathrm{ml}$ round bottomed mixing flask and then to the column was used. Ten $\mathrm{ml}$ fractions were collected. Deionized water was delivered to the mixing flask which also initially contained deionized water for the elution of fractions 1-85. Four normal formic acid was delivered from a reservoir to the mixing volume for the elution of fractions $86-240$. In like manner, $4 \mathrm{~N}$ formic acid which was $0.2 \mathrm{~N}$ in ammonium formate was used for the elution of fractions 241410; $4 \mathrm{~N}$ formic acid $0.4 \mathrm{~N}$ in ammonium formate eluted fractions $411-500$.

Determination of Amino Acids in the Flavor Precursor Fraction Using Ion Exchange and Paper Chromatography

Basic and neutral amino acids were eluted from the Dowex-1 column just described in fraction 1-30 (fraction. I). Most of the water was 
removed from this fraction by lyophilization and the basic amino acids contained in it were determined using the procedure of Spackman et a1. (67), buffers described by Moore et a1. (68), and the ninhydrin reagent developed by Moore and Stein (69). A 1.0 x $50 \mathrm{~cm}$ column of Aminex-MS cation exchange resin (blend Q-50) was employed for the separation of basic amino acids of the flavor precursor fraction. One ml of ninhydrin reagent was added to the $2 \mathrm{~m} 1$ fractions collected from the column. The test tubes were covered and the mixture was heated on a boiling water bath for 30 min to develop color in the tubes which contained ninhydrin positive material. After cooling, the absorbancy at $570 \mathrm{m \mu}$ was determined on each tube using a Beckman DU spectrophotometer. Elution patterns were prepared by plotting $A_{570}$ vs tube number. Amino acids were identified by comparing the elution volume of peaks from the flavor precursor fraction with those of standards determined on the same column.

Acidic amino acids were eluted from the Dowex-1 column in fractions 100-106 and paper chromatographed along with standards in a solvent composed of isobutyric acid, concentrated $\mathrm{NH}_{4} \mathrm{OH}$, and water $66 / 1 / 33$ by volume. The paper was sprayed with $0.5 \%$ ninhydrin in butanol and heated to $100^{\circ} \mathrm{C}$ for 10 minutes to reveal ninhydrin positive compounds.

\section{Gas Chromatography}

Steam distillates from heated defatted peanuts, methylene chloride extracts of the steam distillates from the flavor precursor fraction, molecular distillates of roasted peanuts, aldehydes produced by the ninhydrin reaction on the flavor precursor fraction, and carbonyl compounds regenerated from their 2,4-dinitrophenylhydrazones were all gas chromatographed on a Perkin-Elmer Mode1 800 gas chromatograph equipped with a dual hydrogen flame ionization detector. In each case, the components 
were separated on a 20 foot $\times 1 / 8$ in $0 . d .(0.062$ in $i, d$.$) stainless$ steel column packed with $20 \%$ w/w Apiezon L on Chromosorb W (60-80 mesh). A nitrogen flow rate of $36 \mathrm{ml}$ per minute was used; the temperature was held at $100^{\circ} \mathrm{C}$ for 2 min and then temperature programmed to $200^{\circ} \mathrm{C}$ at $6^{\circ}$ per minute. Retention times of the peaks were normalized by setting that of n-butanal equal to 1.00 .

Trimethylsilyl (TMS) ethers of carbohydrates from the flavor precursor fraction were separated using the same gas chromatograph as described above. A 5\% w/w SE-52 on 60-80 mesh Chromosorb W column ( 8 feet x $1 / 4$ inch o.d.) operated at a nitrogen flow rate of $85 \mathrm{ml}$ per min and temperature programmed from $125-260^{\circ} \mathrm{C}$ at $4^{\circ}$ per minute was employed for these samples. Quantitation was accomplished by comparing peak areas of the sugar TMS ethers in the samples to those of standards prepared and chromatographed in the same manner.

Regeneration of Carbonyls from their 2,4-Dinitrophenylhydrazones

Regeneration of 2,4-dinitrophenylhydrazones was accomplished using the procedure of Ralls (70). For gas chromatography, 6-20 mg of a mixture of 2,4-dinitrophenylhydrazones were mixed with three times their weight of $\alpha$-ketoglutaric acid and heated to $250^{\circ} \mathrm{C}$ for $30 \mathrm{sec}$ in a glass tube sealed with a rubber septum. A sample was removed with a gas tight syringe and immediately introduced onto the gas chromatographic column.

Procedures for the Generation and Identification of Volatile. Compounds from Peanuts, Defatted Peanuts, and the Flavor Precursor Fraction

Finely divided defatted peanut meal was suspended in sodium chloride solution (saturated at room temperature) at a ratio of 1 pound of meal per 2 liters of salt solution. The suspension was stirred and 
refluxed at $105^{\circ} \mathrm{C}$ in a roundbottomed flask for $12 \mathrm{hr}$ or until considerable browning was evident. The refluxed material was steam distilled until no more than a faint caramel aroma existed in the reflux flask. These distillates were sufficiently concentrated that they could be gas chromatographed without further manipulation,

A portion of the flavor precursor fraction isolated from the large Sephadex G-25 column which was saturated with sodium chloride at room temperature and contained a total of $13.5 \mathrm{gm}$ of organic solids was refluxed as previously described for defatted peanuts. After steam distillation of the heated flavor precursor fraction, the $500 \mathrm{ml}$ of steam distillate was extracted 6 times with $20 \mathrm{ml}$ portions of redistilled methylene chloride. Rotary evaporation of the bulk of the methylene chloride gave a material sufficiently concentrated for gas chromatography.

The volatile constituents from normally roasted whole peanuts were isolated by homogenizing the peanuts in an equal weight of heavy mineral oil and then passing this material across a $98^{\circ} \mathrm{C}$ falling film molecular still attached to a vacuum manifold. A vacuum of $10^{-4} \mathrm{~mm}$ of $\mathrm{Hg}$ was maintained by a three stage oil diffusion pump in line with a high capacity roughing pump. Volatile components were collected in a series of two traps caoled to $-196^{\circ} \mathrm{C}$ with liquid nitrogen. The trapped volatiles were cryogenically pumped to a detachable bulb on the vacuum manifold. After the bulb was detached from the vacuum manifold, the contents were allowed to warm until they became liquid. Aliquots of the resulting milky suspension were removed for gas-liquid chromatography.

\section{Preparation of Browning Pigments}

Fifty $m 1$ of the flavor precursor fraction described in the section entitled "Preparation of the Flavor Precursor Fraction" were saturated 
(at room temperature) with $\mathrm{NaCl}$ and refluxed at $106^{\circ} \mathrm{C}$ for $4 \mathrm{hr}$. The resulting material was dialyzed against four changes of deionized water. The material inside the dialysis tubing was evaporated to a small volume and then subjected to gel filtration on a $2 \times 30 \mathrm{~cm}$ column of Sephadex G-25. The brown material which was completely excluded from the gel was collected and lyophilized to dryness. The dry brown powder was examined by infrared and nuclear magnetic resonance spectrometry, and analyzed for carbon, hydrogen, and nitrogen. MMR spectra were run in $D_{2} O$ solution using a Varian Model A-60 spectrometer; infrared spectra were taken on $\mathrm{KBr}$ pellets using a Beckman IR5-A infrared spectrophotometer.

Browning Reactions in Modified Flavor Precursor Fractions

Neutral compounds were removed from a portion of the desalted flavor precursor fraction as described in the section entitled "Separation and Determination of Carbohydrates." Amino acids and other cationic species were eluted from the cation exchange resin with $5 \mathrm{~N} \mathrm{NH}_{4} \mathrm{OH}$ in a manner described by Furuholmen et a1. (72). After evaporation of the amino acid fraction to one-fifth its original volume, it was saturated with $\mathrm{NaCl}$ and adjusted to $\mathrm{pH}$ 6.5. Five $\mathrm{ml}$ of this amino acid fraction was refluxed for $10 \mathrm{hr}$ at $105^{\circ} \mathrm{C}$ in the presence and absence of added carbohydrates. Coagulated material was filtered from the heated solution and absorbancy at $440 \mathrm{~m} \mu$ was determined on the filtrate. The amount of brown pigment formed was determined by comparison of absorbancies of experimental tubes with tubes containing known weights of the brown pigment isolated as described in the section entitled "Preparation of Browning Pigments." 
Results and Discussion

The relative amounts of ultraviolet absorbing material in $\mathrm{NaCl}$ extracts of equivalent amounts of the aleurone grain-protein body fraction of peanuts and defatted peanut cotyledons is shown in Table I. Since the yield of the aleurone grain-protein body fraction of peanuts is about $30 \%$ of the dry fat-free weight of the peanut, the amount of ultraviolet absorbing material in $50 \mathrm{gm}$ of the aleurone grain-protein body fraction was multiplied by a factor of 0.3 to obtain the amount of absorbing material that could be extracted from the weight of the aleurone grain-protein body fraction contained in $50 \mathrm{gm}$ of dry, defatted peanuts .

If a given absorbing peak originated exclusively from the aleurone grain-protein body fraction, then the amount of absorbing material isolated from this fraction would be the same as that isolated from an equivalent amount of defatted peanut cotyledons.

The results indicated that the $308 \mathrm{~m} \mu$ absorbing material arose almost exclusively from outside the aleurone grain-protein body fraction; the $262 \mathrm{m \mu}$ absorbing material appeared to be distributed throughout the particulates of the parenchyma cells of the cotyledons and the $254 \mathrm{~m} \mu$ absorbing material seemed to be concentrated somewhat in the aleurone grain-protein body fraction.

Mason and Waller (7) demonstrated that the aleurone grain-protein body fraction produced typical peanut aroma upon roasting. Since they also showed that material in the peaks absorbing at $262 \mathrm{~m} \mu$ gave peanut aroma upon heating in the dry state, it seems evident that precursors of peanut flavor, even though they reside in part in the aleurone grainprotein body fraction, are also distributed with nearly equal frequency 
TABLE I

YIELD OF ULTRAVIOLET ABSORBING MATERIALS

IN DEFATTED PEANUT COTYLEDONS AND

ALEURONE GRAIN-PROTEIN

BODY FRACTIONS

\begin{tabular}{lccc}
\multicolumn{1}{c}{ Starting Material } & $\begin{array}{c}\text { Units of U1traviolet Absorbing } \\
\text { Material at } \lambda \text { Max }\end{array}$ \\
\hline $\begin{array}{l}\text { Aleurone Grain-Protein } \\
\text { Body Fraction (50 gm) }\end{array}$ & $\frac{254 \mathrm{m \mu}}{262 \mathrm{~m} \mu}$ & $\frac{308 \mathrm{~m} \mu}{4}$ \\
$\begin{array}{l}\text { Aleurone Grain-Protein } \\
\text { Body Fraction Equivalent } \\
\text { to 50 gm of Defatted } \\
\text { Peanut Cotyledons }\end{array}$ & 290 & 405 & 290 \\
$\begin{array}{l}\text { Defatted Peanut } \\
\text { Cotyledons (50 gm) }\end{array}$ & 87 & 722 & \\
\hline
\end{tabular}


in other locations in the cotyledon.

Aldehydes were generated from neutral amino acids in the flavor precursor fraction and their identity determined as described in the section entitled "Determination of Neutral Amino Acids in the Flavor Precursor Fraction."

The results indicated that the flavor precursor fraction contained isoleucine, phenylalanine, and valine along with smaller quantities of alanine, leucine, tyrosine, and $\alpha$-amino-n-butyric acid.

Anionic constituents of the flavor precursor fraction were separated on a Dowex-1 formate column as described in the section entitled "Separation of Anionic Constituents of the Flavor Precursor Fraction." The elution pattern of this column is shown in Figure 1 . Peak I was ninhydrin positive and probably contained neutral and basic amino acids as well as other neutral components such as carbohydrates. Fraction II was also ninhydrin positive and paper chromatography showed it to contain glutamic acid, aspartic acid, $\mathrm{NAD}^{+}$and two unknown ninhydrin positive compounds having $R_{F}$ values of 0.18 and 0.77 respectively in the solvent described in the section entitled "Determination of Amino Acids in the Flavor Precursor Fraction Using Ion Exchange and Paper Chromatography." The identity of the other peaks eluted from this column are unknown but their ultraviolet spectra in acidic, basic and neutral media are similar to the spectra of nucleotides ( $\lambda$ max in the area of $260 \mathrm{~m} \downarrow$ ). No peaks were detected after peak VIII.

Fraction I from the Dowex-1 column was chromatographed on the $50 \mathrm{~cm}$ Aminex-MS column which was described in the section entitled "Determination of Amino Acids in the Flavor Precursor Fraction Using Ion Exchange and Paper Chromatography." Amino Acids contained in the flavor precursor 


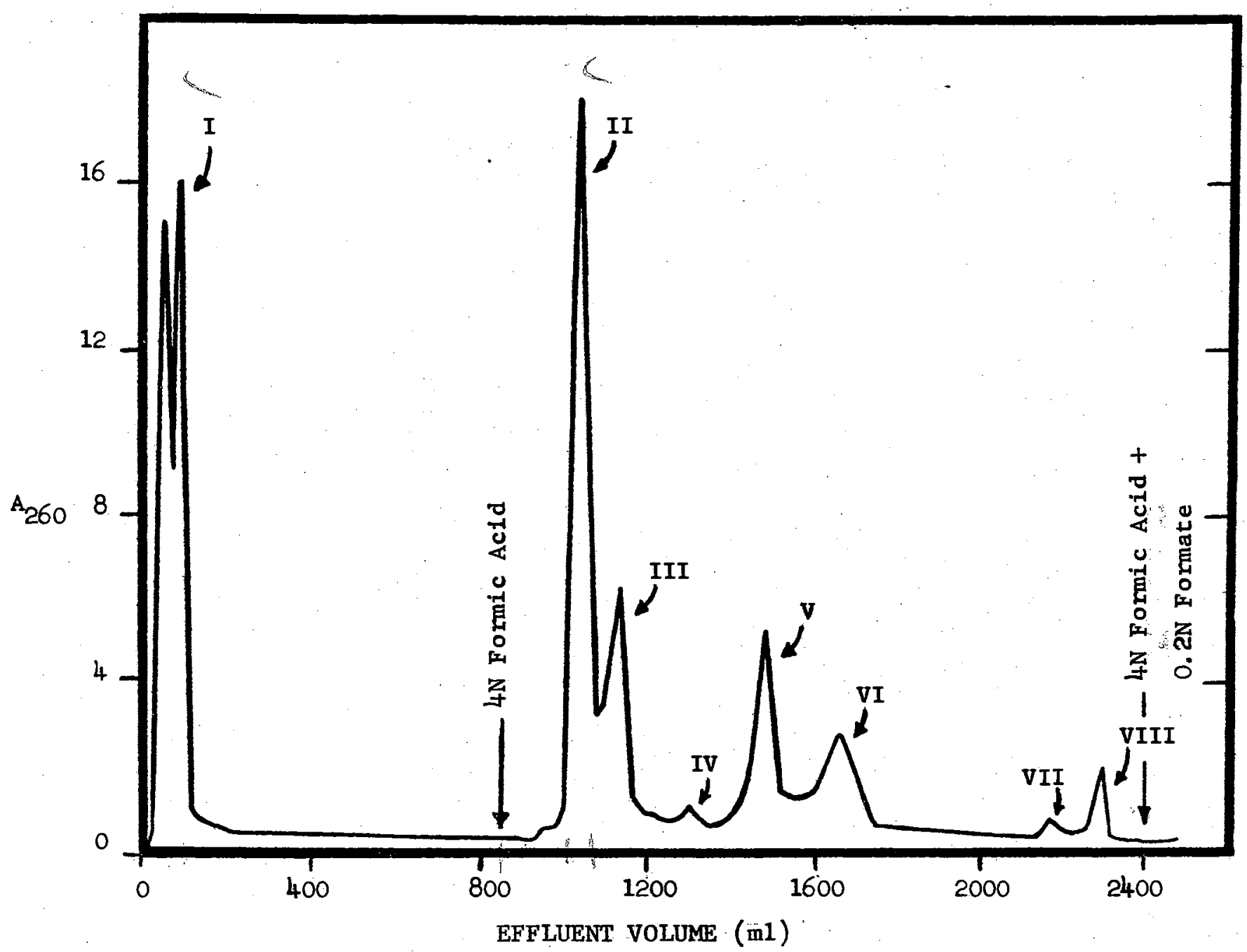

Figure 1. Elution Pattern of Dowex-1 Formate Column 
fraction identified using this procedure were tryosine and/or pheny1alanine, lysine, tryptophan, histidine, and ammonia. No arginine was detected although it has been shown to occur at relatively high concentrations in raw peanuts (Chapter IV). Arginine probably was present in the flavor precursor fraction but was not detected since the arginine was probably eluted from the column as a broad diffuse peak that could not be distinguished from the background ninhydrin color.

Table II contains a comparison of volatile constituents from heated defatted peanut meal, the heated flavor precursor fraction, and a molecular distillate of normally roasted peanuts. Gas chromatographic characteristics are given for regenerated carbonyl compounds as well as distillates, Because condensates from the flavor precursor fraction had to be concentrated by extraction into methylene chloride, the solvent peak obliterated the peaks representing lighter components. For this reason these were listed as "not analyzed" in Table II.

The data of Table II show: a) In each of the three cases, defatted peanuts, flavor precursor fraction, and roasted peanuts, many of the components were carbonyl compounds; b) Relative retention data which indicated that many of the same components were present in a11 three cases. The exceptions included the presence of the component from distillates of defatted peanuts having a relative retention of $1 \% 01$ which was not present in the other two cases and the 4.56 component which was not detected in the distillates from the flavor precursor fraction but which probably occurred in the distillates of roasted peanuts (the 4.68 component). The regenerated carbonyls of the precursor fraction contained a component having a relative retention of 5.72 which was detected in distillates of roasted peanuts but not in distillates from 
TABLE II

\section{RELATIVE RETENTIONS OF COMPONENTS ISOLATED \\ FROM ROASTED PEANUTS, DEFATTED PEANUTS \\ AND THE FLAVOR PRECURSOR FRACTION}

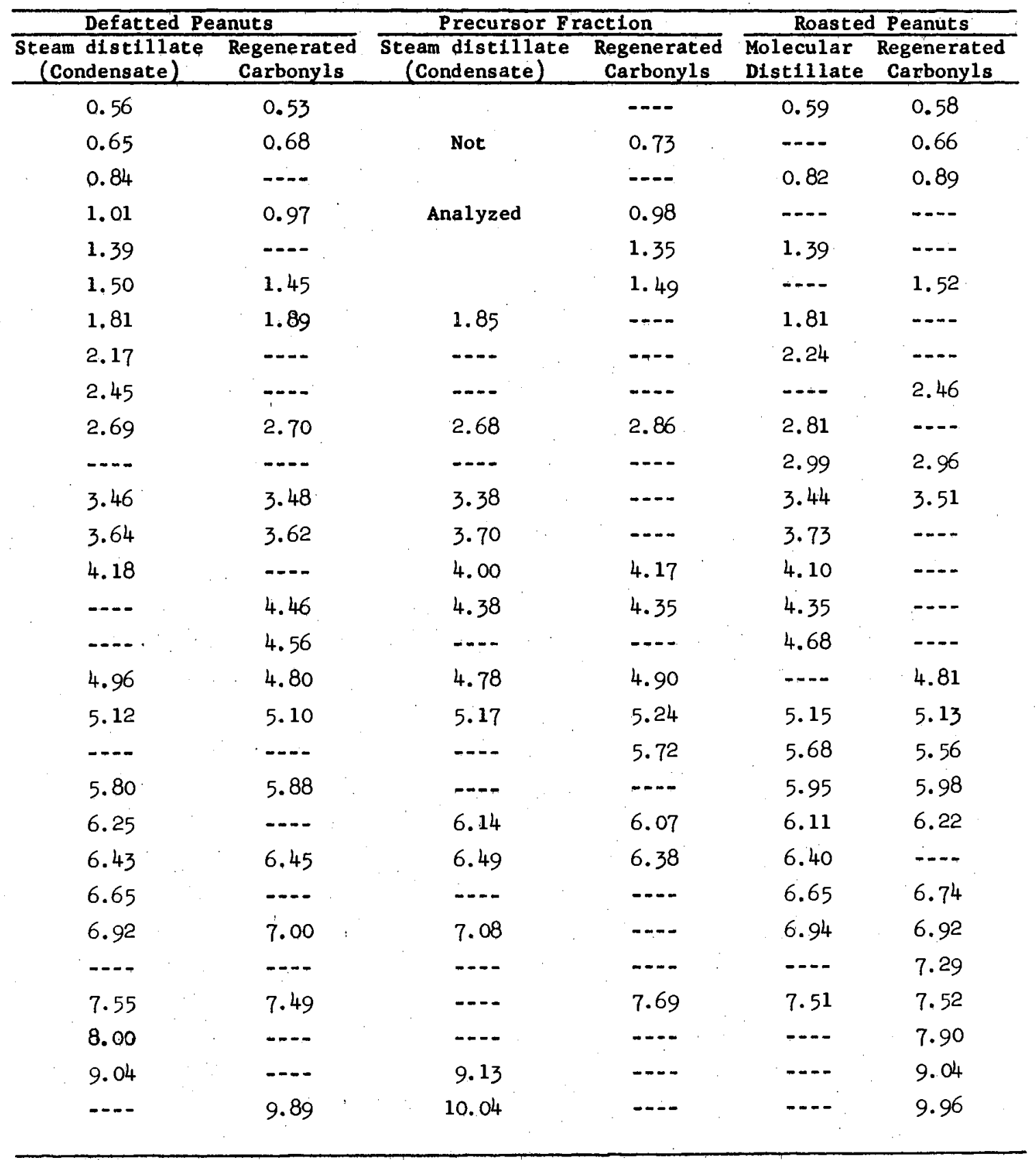


defatted peanuts. Compounds having relative retentions of 2.99 and 7.29 were present in distillates and/or regenerated carbonyls of roasted peanuts but were absent in the other two cases.

It is possible that some components were present in the various systems but did not occur in sufficient quantities to allow their detection as distinct peaks or shoulders in the gas chromatograms. Thus, since the relative retentions of the individual peaks compared in Table II generally agreed within $2-3 \%$, the major differences in components of the various systems were probably quantitative rather than qualitative. Since neutral lipid was absent in the defatted peanuts and in the flavor precursor fraction and since these fractions produced many of the same volatile components as conventionally roasted peanuts, it was concluded that neutral lipids have little importance as precursors of pea nut flavor. This was in accordance with the findings of Iverson et al. (73) that there was no difference in fatty acid content of peanut triglycerides before and after roasting. However, Casey et al. (74) showed that the nature of the medium in which flavor producing reactions occurred was important in the quantitative distribution of low boiling volatiles produced during heating of many foods.

Thus it was concluded that the qualitative nature of the volatiles produced from roasted peanuts, heated defatted peanuts or the heated flavor precursor fraction was similar and that the quantitative differences of volatile components arose primarily from differences in the reaction medium.

Table III gives the identity of carbohydrates identified in the flavor precursor fraction using methods described in the section entio tled "Separation and Determination of Carbohydrates." Unidentified 
TABLE III

SUGARS FOUND IN THE FLAVOR PRECURSOR

FRACTION OF ARGENTINE PEANUTS AS

DETERMINED BY GAS CHROMATOGRAPHY

OF THEIR TRIMETHYLSILYL ETHERS

\begin{tabular}{|c|c|c|c|}
\hline Component & Identity & $\begin{array}{l}\text { Relative } \\
\text { Retention }\end{array}$ & $\begin{array}{c}\text { Mg Sugar/gm } \\
\text { Organic Solids in } \\
\text { Precursor Fraction }\end{array}$ \\
\hline 1 & Unknown & 0.41 & 3.9 \\
\hline 2 & Arabinose & 0.50 & Trace \\
\hline 3 & Unknown & 0.55 & Trace \\
\hline 4 & $\beta$-Xylose & 0.65 & 8.7 \\
\hline 5 & Fructose & 0.70 & 15.3 \\
\hline 6 & $\alpha$-galactose & 0.75 & Trace \\
\hline 7 & $\alpha-g l u c o s e$ & 0.78 & Trace \\
\hline 8 & $\beta$-glucose & 0.82 & Trace \\
\hline 9 & $\begin{array}{l}\text { N-acetyl- } \\
\text { galactosamine } \\
\text { or } \beta \text {-galactose }\end{array}$ & 0.87 & 100.4 \\
\hline 10 & Sucrose & 1.17 & 161.8 \\
\hline 11 & Unknown & 1.28 & 5.5 \\
\hline 12 & Unknown & 1.53 & 25.8 \\
\hline
\end{tabular}


sugars were present in trace amounts.

The brown pigment isolated as described in the section entitled "Preparation of Browning Pigments" had an elemental analysis of C $37.86 \%$, H $5.01 \%, \mathrm{~N} 3.97 \%$, ash $12.70 \%$, and $\mathrm{O}$ (by difference) $40.46 \%$. The emper ical formula was $\mathrm{C}_{11} \mathrm{H}_{18} \mathrm{O}_{8} \mathrm{~N}$. The fact that most of the pigment was excluded from Sephadex G-25 indicated an average molecular weight in excess of 3000 .

NMR spectra of the isolated pigment in $\mathrm{D}_{2} \mathrm{O}$ (Figure 2) showed that about 8 of the 18 protons exchanged instantly with $\mathrm{D}_{2} \mathrm{O}$. This fact coupled with the strong absorption between 3500 and $3700 \mathrm{~cm}^{-1}$ in the infrared spectrum (Figure 3) was interpreted to mean that these protons were hydroxyl or enolic. The strong absorption between 1500 and $1700 \mathrm{~cm}^{-1}$ was thought to arise from carbonyl groups conjugated with double bonds. However, since evidence for protons of the $-\mathrm{C}=\mathrm{C}$ - type was lacking in the NMR spectrum, it was postulated that the double bonds indicated in the infrared spectrum were enolic and that the protons had exchanged with $\mathrm{D}_{2} \mathrm{O}$. Absorption in the NMR spectrum between 3.8 and $4.8 \mathrm{ppm}$ indicated approximately 8 protons of the (H)-C-OH type. The remaining protons were probably of the type $H-\mathcal{G}-\mathbb{A}$ as indicated by weak absorption at $0.5 \mathrm{ppm}$.

These spectral data coupled with elemental analysis indicated that the brown polymer was probably composed of residues from both carbohy drates and amino acids at a frequency of about two, six carbon sugars to one amino acid nitrogen atom. Oxidation or losses of the elements of water along with facile rearrangements could account for the presence of enolic protons.

Neutral and cationic species in the desalted flavor precursor fxaction were separated and treated as described in the section entitled 


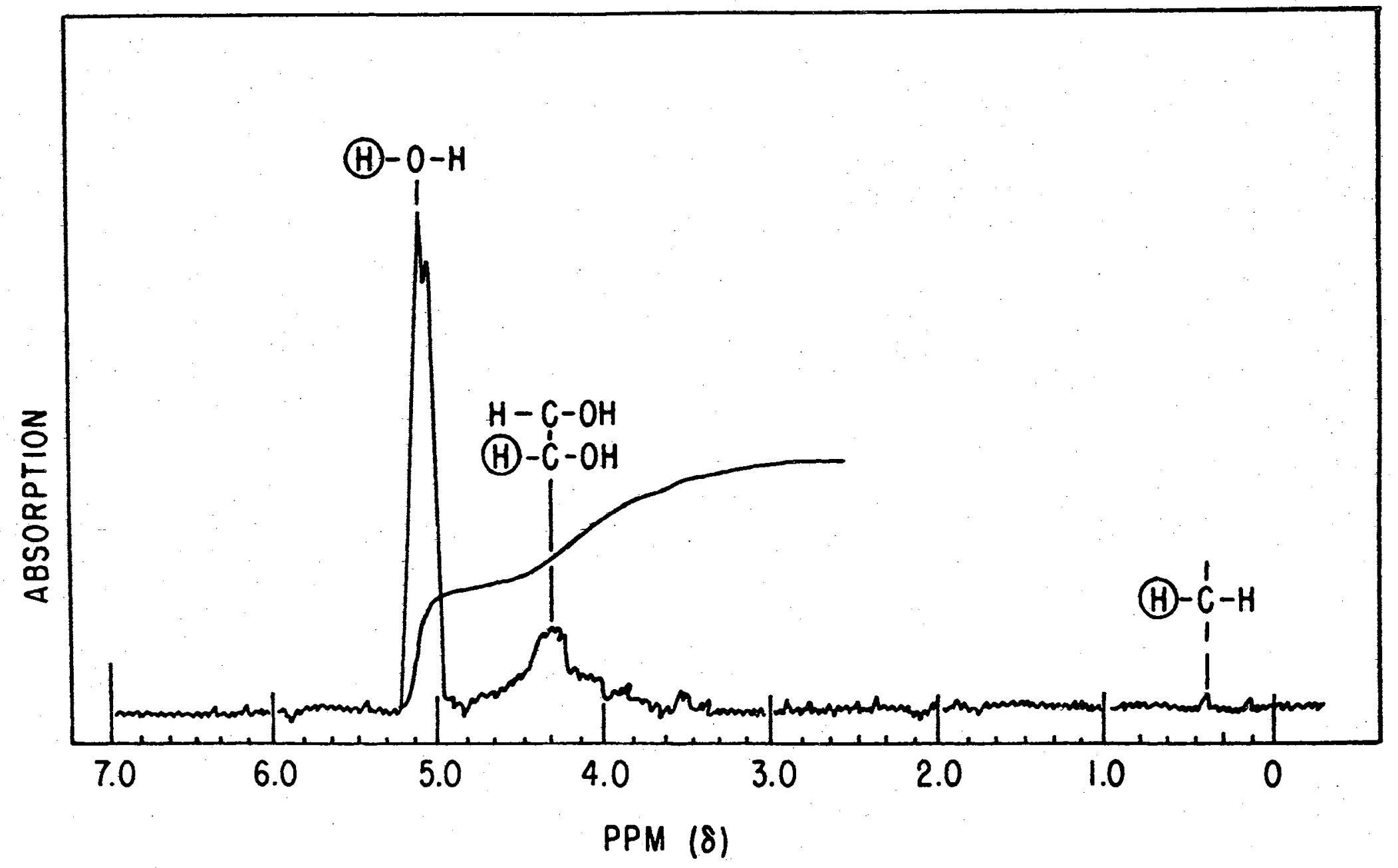

Figure 2. NMR Spectrum of the Isolated Brown Pigment in $\mathrm{D}_{3} \mathrm{O}$ 


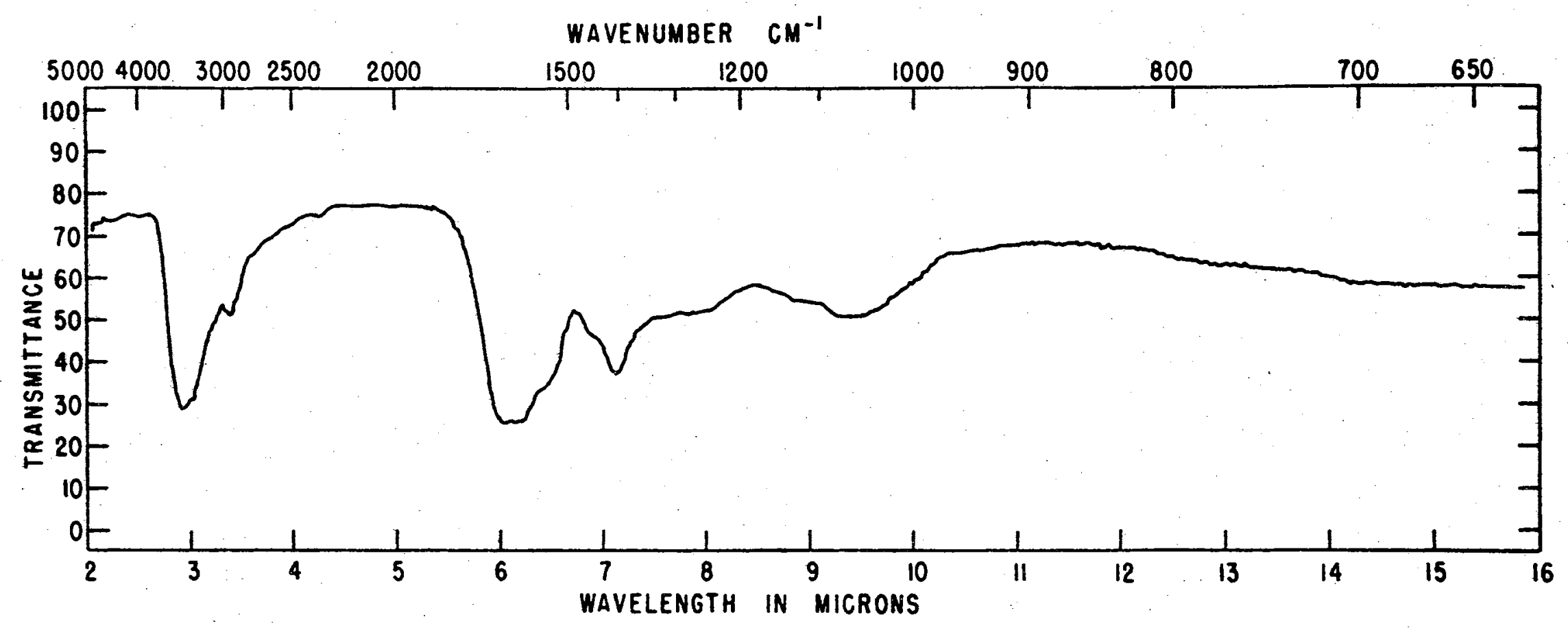

Figure 3. Infrared Spectrum of the Isolated Brown Pigment on a $\mathrm{KBr}$ Disc 
"Browning Reactions in Modified Flavor Precursor Fractions." Table IV shows that significant browning occurred in the cationic fraction only in the presence of added carbohydrates. Fructose was a more efficient reactant in the browning reaction than glucose or sucrose at the same concentration. Maximum browning occurred in the reaction that contained glucose and fructose. The reaction mixture containing sucrose did not brown readily: which was the expected result if browning was dependent on the presence of a reducing group. Song and Chichester (38) demonstrated that a reducing group is required for significant browning.

Since the reaction mixture containing both glucose and fructose did not produce as much brown pigment as would have been expected from the sum of the pigment produced from glucose and fructose alone, the amount of cationic constituents in the mixture containing both glucose and fructose probab1y was the limiting reactant.

To the extent that non-enzymatic browning indicated the formation of compounds which may play a role in the flavor of heated foods (Chapter II) amino acids and/or other cationic constituents must be important in the production of typical peanut flavor. 
TABLE IV

BROWNING OF CATIONIC CONSTITUENTS OF THE

FLAVOR PRECURSOR FRACTION IN THE

PRESENCE AND ABSENCE OF

ADDED CARBOHYDRATES

\begin{tabular}{lc}
\multicolumn{1}{c}{ Reactant Added* } & $\begin{array}{c}\text { mg pigment formed } \\
\text { in } 10 \text { hours heating }\end{array}$ \\
\hline No additions ** & 0.00 \\
$1 \mathrm{ml} 0.5 \mathrm{M}$ fructose & 1.54 \\
$1 \mathrm{ml} 0.5 \mathrm{M}$ glucose & 1.39 \\
$1 \mathrm{ml} 0.5 \mathrm{M}$ sucrose & 0.68 \\
glucose and fructose & 1.85 \\
sucrose and fructose & 1.64 \\
sucrose and glucose & 1.48 \\
sucrose, glucose and fructose & 1.63 \\
\hline
\end{tabular}

*A11 reaction mixtures contained $5 \mathrm{ml}$ of the cationic fraction from the Dowex-50 column as described in the procedure.

**This mixture browned slightly and was used as a blank. 
CHAPTER IV

\section{PRECURSORS OF TYPICAL AND ATYPICAL ROASTED PEANUT FLAVOR}

\section{Introduction}

Earlier work from this laboratory described the isolation of a flavor precursor fraction of raw peanuts which consisted of low molecular weight compounds rather than proteins or polysaccharides. Paper chromatography of the fraction containing the flavor precursors indicated further the presence of ninhydrin positive and basic compounds (7). Any compound that is a flavor precursor must, by nature, be a substance of low volatility which can be converted to a more volatile one during heating. The authors' approach to the peanut flavor precursor problem was to analyze the heated and unheated flavor precursor fraction or extracts of raw and roasted peanuts. Knowing the volatile compounds produced $(11,13,14,75)$ and the non-volatile material degraded allowed the postulation of a mechanism to explain the decrease in flavor precursor concentration during roasting and the production of compounds which exhibit typical roasted peanut flavor. A similar approach has been employed in cocoa flavor precursor work $(21,24,25)$.

\section{Procedures}

\section{Determination of Peanut Maturity}

Peanuts having dark colored interior pericarp surfaces and thin pink colored testa were classed as mature; those having light colored 
interior pericarp surfaces and fleshly white testa were classed as im-

mature. Peanuts falling between these extremes were classified as intermediate in maturity. The peanuts from the maturity classes used in the work presented here were large enough to be retained on a $15 / 64 \times 3 / 4-$ inch screen.

\section{Subjective Analysis of Peanut Flavor}

A flavor panel consiting of five members was instructed to rate the flavor of four coded samples of ground, roasted plus coded and uncoded standards of Argentine Spanish peanuts. The Argentine Spanish standard has consistently proven to have superior organoleptic properties over several years of testing. The organoleptic evaluation was reported on rating sheets. 1ike that shown in Figure 4. Mean preference rank was obtained by taking the average of the preference rank given by each panel member to a particular sample. The mean preference rank is an estimate of peanut flavor in numerical terms as compared to a standard. The mean preference ranks reported in this thesis represent an average of two separate determinations. In each replication, the sample in question was roasted immediately before it was presented to the panel. Due to variations in the roasting process and the inability of the pane 1 to detect subtle flavor differences, the two replications of the mean preference rank were seldom exactly the same. For example, sample 2 (Table VI) had a mean preference rank of 2.4 ; sample 1 had a mean preference rank of 2.2. The former sample was considered to have better flavor because the panel rated it, with respect to flavor, superior--or equal-to the standard (Figure 4) more consistently than the latter one. According to taste panel results, samples 1,3 and 5 had flavor somewhat inferior to samples 2,4 and 6 . The difference in flavor of 
Date

Taster

Description

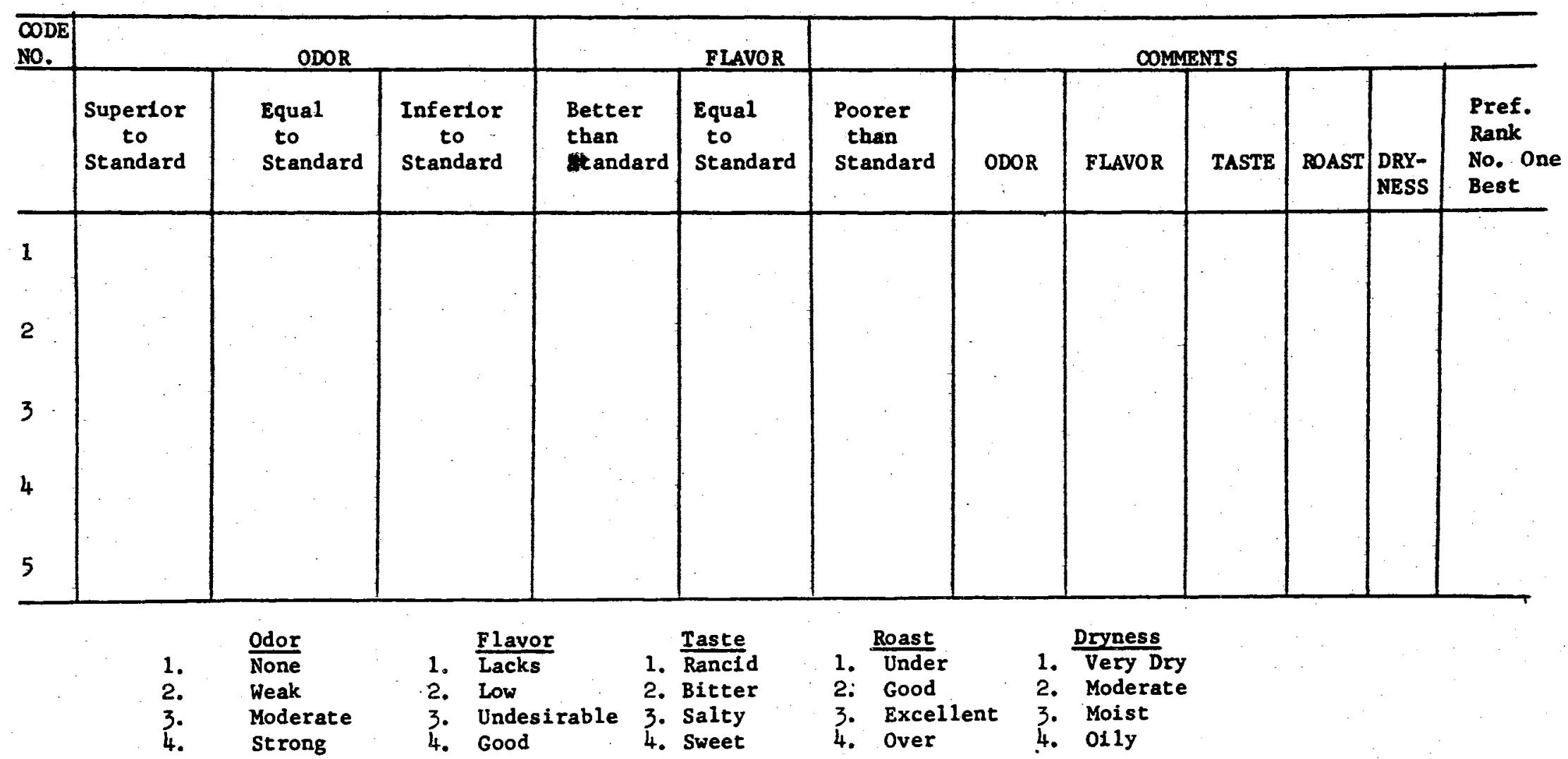

Figure 4. Form Used by Each Panel Member

in Organoleptic Evaluation 
the peanut samples used in this work was due to the degree of maturity of the samples. All samples were of the same variety, grown at the same location, and processed in the same manner. Samples 1, 3 and 5 were harvested September 18, 1965, and were more immature; samples 2,4 and 6 were harvested on October 9, 1965. The mean preference ranks for samples $1,2,3$ and 4 were $2.2,2.4,3.6$ and 2.4 respectively.

\section{Preparation of Peanuts for NaCl or Perchloris Acid Extraction}

Raw peanuts ground with a food grinder or ground roasted peanuts were extracted with redistilled $n$-hexane in a soxhlet extractor. After the solvent was removed by evaporation, the dry peanuts were ground to a fine powder and the fat-free meal was stored in tightly stoppered bottles at room temperature prior to further extraction.

\section{Preparation of a Peanut Flavor Precursor Fraction}

The flavor precursor fraction from $2 \mathrm{~kg}$ of raw fat-free peanuts was obtained by extraction with 15 liters of $1 \mathrm{M}$ NaCl solution. The extract was concentrated to 1 liter by rotary evaporation and the evaporated extract was subjected to gel filtration on a 10.8 liter column of Sephadex G-25. From the Sephadex column was collected the flavor precursor fraction described by Mason and Waller (7).

\section{Perchloric Acid Extraction}

Ground fat-free meal was stirred with $3 \mathrm{~N}$ perchloric acid (25 $\mathrm{ml}$ of $3 \mathrm{~N} \mathrm{HClO}_{4}$ per gm of fat-free meal) on a magnetic stirrer for 1 hour at $4^{\circ} \mathrm{C}$. The acidic extract was centrifuged at $10,000 \times \mathrm{g}$ in the cold to remove insoluble material. The $\mathrm{pH}$ of the supernatant liquid was adjusted to 7.0 with saturated $\mathrm{KOH}$; the $\mathrm{KClO}_{4}$ formed was removed by high speed centrifugation at $4^{\circ} \mathrm{C}$. The clear supernatent liquid was lyophilized to 
dryness and redissolved in a minimum volume of $0.2 \mathrm{~N}$ citrate buffer at pH 2.2. Hydrolysis of amide nitrogen was not a problem as judged by the absence of hydrolysis of glutamine and asparagine standards which were treated in the same manner.

Preparation of Samples for Carbohydrate Analysis

Fat-free meal (0.5 gram) was extracted for 24 hours with $100 \mathrm{~m} 1$ of $80 \%$ ethanol in a soxhlet extractor. The volume of the extract was reduced to about $15 \mathrm{ml}$ by rotary evaporation and placed on a $0.8 \times 20 \mathrm{~cm}$ column of Amberlite CG-120 (100-200 mesh) in the sodium form. Neutral compounds were eluted from the column with $50 \mathrm{ml}$ of deionized water and the eluate was lyophilized to a solid residue. The residue was dissolved in $2.0 \mathrm{ml}$ of $\mathrm{N}, \mathrm{N}-$ dimethylformamide and allowed to stand at room temperature for about one hour to achieve dissolution. The following additions were made to the dimethylformamide solution in the order: $0.5 \mathrm{ml}$ of pyridine, $0.4 \mathrm{~m} 1$ of hexamethyldisilazane and $0.2 \mathrm{ml}$ of trimethylchlorosilane. One m1 of a standard solution containing $8 \mu$ mole each of ribose, fructose, glucose, inositol, and sucrose was treated in the same manner as the samples from peanuts. Sugar concentrations were calculated by comparison of sample peak areas with corresponding peak areas of the standard.

\section{Gas Chromatography of Trimethylsilyl Ethers}

Gas chromatography was conducted on a Perkin-Elmer model 801 gas chromatograph equipped with a hydrogen flame ionization detector. A 6 foot $\times 1 / 4$ inch o.d. glass column packed with $5 \%(w / w)$ SE-52 on $100-$ 110 mesh Gas Chrom Q operated at a nitrogen flow rate of $60 \mathrm{ml}$ per minute and temperature programmed from $120-250^{\circ} \mathrm{C}$ was used to separate 
the trimethylsilyl derivatives.

Amino Acid Analyses

Amino acid contents of perchloric acid extracts obtained as previously described were determined with a Beckman 120-C Amino Acid Analyzer using Beckman PA-28 and PA-35 resins respectively.

\section{Gross Changes in the Flavor Precursor Fraction During Heating}

A NaCl solution (saturated at room temperature) of the flavor precursor fraction obtained in the manner previously described which contained 13.5 grams of total organic solids was refluxed for 15 hours at $105^{\circ} \mathrm{C}$. Total ninhydrin positive material (76), pentoses (77), carbohydrates (78) reducing sugars (79), and organic solids (64) were determined before and after refluxing using published procedures.

\section{Results and Discussion}

The Effect of Heating on the Flavor Precursor Fraction

The heated and unheated flavor precursor fractions were analyzed as previously described. Table $\mathrm{V}$ shows that total carbohydrates and amino acids decreased, pentose sugars and total organic solids remained relatively constant, and reducing activity increased sharply during refluxing. The biuret test (80) indicated that the flavor precursor fraction contained only traces of peptides after residual protein was precipitated.

The results of the analysis for ninhydrin positive material and total sugars indicated that amino acids and carbohydrates had reacted in some manner and that both were modified during the process. The observed increase in reducing power was explained by hydrolysis of sucrose or by a process in which carbohydrates were converted to reductones (37). The fact that total organic solids decreased only slightly during the 
TABLE V

CHANGES IN COMPOSITION OF THE FLAVOR PRECURSOR

FRACTION DURING REFLUXING

\begin{tabular}{|c|c|c|c|c|}
\hline \multirow[b]{2}{*}{ Treatment } & \multicolumn{3}{|c|}{ Total in Milligrams } & \multirow[b]{2}{*}{$\begin{array}{l}\text { Percent } \\
\text { Change }\end{array}$} \\
\hline & $\begin{array}{l}\text { Before } \\
\text { Heating }\end{array}$ & $\begin{array}{l}\text { After } \\
\text { Heating }\end{array}$ & $\begin{array}{l}\text { Change } \\
\text { During } \\
\text { Heating }\end{array}$ & \\
\hline Ninhydrin (as leucine) & 517 & 263 & -254 & 49.1 \\
\hline Orcinol (as ribose) & 16 & 15 & -1 & 6.3 \\
\hline Anthrone (as glucose) & 8915 & 6360 & -2555 & 28.6 \\
\hline $\begin{array}{l}\text { Alkaline copper } \\
\text { (as glucose) }\end{array}$ & 470 & 6400 & +5930 & 1261.9 \\
\hline Total Organic Solids & 13500 & 12750 & -750 & 5.6 \\
\hline
\end{tabular}


heating process meant that most of the material produced during heating was of low volatility.

The formation of large amounts of polymeric material was evidenced by formation of considerable insoluble dark colored material in the flavor precursor fraction during heating. When a portion of the heated saline solution was dialyzed against delonized water, the brown material remained inside the dialysis tubing. The nondialyzable material was lyophilized to dryness, redissolved in a minimum of water, and subjected to gel filtration on a $20 \times 3 \mathrm{~cm}$ column of Sephadex G-25. The brown material which was completely excluded from the gel was collected, lyophilized and analyzed for carbon, nitrogen, hydrogen, and ash. The analysis (C $37.86, \mathrm{H} 5.01, \mathrm{~N} 3.97$, ash 12.70 , and 0 by difference 40.46) corresponded to an empirical formula of $\mathrm{C}_{11} \mathrm{H}_{10} \mathrm{O}_{\theta} \mathrm{N}$. The results of these experiments indicated that amino acids and carbohydrates of the flavor precursor fraction were undergoing chemical changes.

\section{Changes in Individual Amino Acid Concentrations During Roasting}

Amino acids can give rise to aldehydes by strecker degradation and can serve as the source of nitrogen for the formation of pyrazine compounds $(30,37)$. That these compounds are produced during roasting of peanuts was indicated by recently published results $(13,14,75)$ in which pyrazines and aldehydes were shown to represent the major classes of organic compounds evolved from peanuts during roasting. Data presented in Tables VI and VII indicated very strongly that amino acids and sugars were the precursors of these volatile flavor components in roasted peanuts .

Table VI shows amino acid concentrations (expressed in $\mu$ moles per gm of fat-free peanut meal) in raw and roasted peanuts and the ratio: 
TABLE V I

AMINO ACID CONCENTRATIONS (HMOLES/GRAM OF FAT-FREE MEAL)

AND RAW/ROASTED RATIOS IN FULLY MATURE

AND INTERMEDIATE MATURITY PEANUTS

\begin{tabular}{|c|c|c|c|c|c|c|c|c|c|c|c|c|c|}
\hline \multirow{4}{*}{ Amino Acid } & \multirow{2}{*}{\multicolumn{7}{|c|}{ FULLY MATURE }} & \multirow{2}{*}{\multicolumn{6}{|c|}{ INTERMEDIATE MATURITY }} \\
\hline & & & & & & & & & & & & & \\
\hline & \multicolumn{3}{|c|}{ Sample I } & & \multicolumn{3}{|c|}{ Sample 2} & \multicolumn{3}{|c|}{ Sample 3} & \multicolumn{3}{|c|}{ Sample 4} \\
\hline & Raw & Roasted & Ratio & & Raw & Roasted & Ratio & Raw & Roasted & Ratio & Raw & Roasted & Ratio \\
\hline Aspartic acid & 0.58 & 0.73 & 0.79 & & 0.88 & 0.58 & 1.52 & 0.58 & 0.44 & 1.33 & 1.02 & 0.88 & 1.16 \\
\hline Threonine & 0.73 & 0.58 & 1.26 & & 0.29 & 0.12 & 2.42 & 0.88 & 0.58 & 1.52 & 0.44 & 0.29 & 1.52 \\
\hline Serine & 1.17 & 0.88 & 1.33 & & 0.58 & 0.44 & 1.32 & 1.61 & 1.02 & 1.58 & 1.75 & 0.88 & 1.99 \\
\hline $\begin{array}{l}\text { Asparagine and } \\
\text { Glutamine }\end{array}$ & 2.19 & 1.32 & 1.66 & & 2.92 & 0.88 & 3.32 & 2.49 & 1.02 & 2.44 & 4.53 & 1.46 & 3.10 \\
\hline Proline & 1.32 & 1.17 & 1.13 & & 1.02 & 0.58 & 1.76 & 1.02 & 0.88 & 1.17 & 2.19 & 1.02 & 1.98 \\
\hline Glutamic Acid & 7.02 & 3.95 & 1.78 & & 7.89 & 2.34 & 3.37 & 7.02 & 3.36 & 2.09 & 11.26 & 3.07 & 3.67 \\
\hline Glycine & 1.17 & 1.02 & 1.15 & & 0.44 & 0.44 & $1.00^{\circ}$ & 1.75 & 1.17 & 1.50 & 1.61 & 0.73 & 2.21 \\
\hline Alanine & 4.68 & 3.22 & 1.45 & & 2.05 & 1.32 & 1.55 & 8.19 & 5.41 & 1.51 & 5.56 & 3.36 & 1.65 \\
\hline Valine & 1.32 & 1.02 & 1.29 & & 0.73 & 0.29 & 2.52 & 1.75 & 1.02 & 1.72 & 1.90 & 0.88 & 2.16 \\
\hline Unknown & 2.92 & $1: 32$ & 2.21 & & 4.09 & 0.44 & $9 \cdot 30$ & 1.90 & 0.73 & 2.60 & 1.46 & 0.29 & 5.03 \\
\hline Methlonine & 0.29 & 0.15 & 1.93 & & 0.29 & 0.15 & 1.93 & 0.15 & 0.15 & 1.00 & 0.29 & 0.15 & 1.93 \\
\hline Isoleucine & 0.73 & 0.58 & 1.27 & & 0.44 & 0.29 & 1.52 & 0.88 & 0.44 & 2.00 & 0.88 & 0.44 & 2.00 \\
\hline Leucine & 0.58 & 0.44 & 1.32 & - & 0.44 & 0.15 & 2.93 & 0.73 & 0.44 & 1.56 & 0.73 & 0.44 & 1.66 \\
\hline Tyrosine & 0.44 & 0.44 & 1.00 & & 0.15 & 0.15 & 1.00 & 0.73 & 0.44 & 1.66 & 0.29 & 0.15 & 1.93 \\
\hline Phenylalanine & 2.19 & 2.63 & 0.83 & & 2.34 & 1.61 & 1.46 & 2.05 & 1.32 & 1.55 & 1.75 & 1.46 & 1.20 \\
\hline B-alanine & trace & trace & $\cdots$ & & 0.15 & trace & -- & trace & trace & -- & trace & 0.15 & -- \\
\hline Lysine & 0.88 & 0.58 & 1.52 & & 0.44 & 0.15 & 2.93 & 0.88 & 0.73 & 1.21 & 0.73 & 0.29 & -2.52 \\
\hline Histidine & 0.44 & 0.29 & 1.52 & & 0.29 & 0.15 & 1.93 & 0.58 & 0.29 & 2.00 & 0.58 & 0.29 & 2.00 \\
\hline Ammonia & 1.75 & 4.09 & 0.43 & & 0.73 & 0.58 & 1.26 & 2.34 & 4.97 & 0.47 & 2.63 & 6.43 & 0.41 \\
\hline Arginine & 1.46 & 1.17 & 1.25 & & 1.46 & 1.32 & 1.11 & 1.32 & 2.19 & 0.60 & 1.61 & 1.17 & 1.38 \\
\hline Tryptóphan & 0.29 & 0.29 & 1.00 & & 0.44 & 0.29 & 1.52 & 0.73 & 0.44 & 1.66 & 0.58 & 0.29 & 2.00 \\
\hline
\end{tabular}


$\mu$ moles per gm raw / $\mu$ moles per gm roasted. Several conclusions were drawn from examination of these data. First, regardless of the maturity category studied, glutamic acid, asparagine-glutamine, the unknown amino acid, phenylalanine, and alanine made up most of the total free amino acids and probably were the most important as flavor precursors. Secondly, with the exception of the under-roasted sample (Sample No, 1) the raw/roasted ratios for a given amino acid in different samples were fairly consistent. The raw/roasted ratios of the under-roasted sample were consistently lower than the average of the other three samples with the exception of the very minor components: methionine, lysine, and arginine. This result would be predicted if destruction of amino acids were a function of the duration of roasting.

These two facts show that free amino acids were destroyed during roasting to a degree approximately proportional to their original concentration. Further, although initial concentrations of some free amino acids appeared to be a function of maturity, the proportion of each degraded during heating was fairly constant from sample to sample.

The observations prompted the authors to consider kinetic control as the control mechanism in the conversion of amino acids to flavor compounds during roasting. If kinetic control were independently operative (i.e., if available energy were not a limiting factor) one would expect the raw/roasted ratios for a given amino acid in different samples to remain relatively constant provided the samples were roasted to the same extent.

Breakdown of all carbohydrates in the better flavored peanuts (Table VII) in each maturity class, was of the order of 4 to $10 \mu$ moles per gm, assuming that all sucrose lost was converted to fructose and 
TABLE VII

GAS CHROMATOGRAPHIC ANALYSIS OF TRIMETHYLSILYL

ETHERS OF CARBOHYDRATES FROM RAW

AND ROASTED PEANUTS

\begin{tabular}{|c|c|c|c|c|c|}
\hline $\begin{array}{c}\text { Sample } \\
\text { Designation }\end{array}$ & Carbohydrate & $\begin{array}{l}\text { Raw } \\
\text { Hmole/ } \\
\text { gm }\end{array}$ & $\begin{array}{c}\text { Roasted, } \\
\text { Hmole/ } \\
\text { gm }\end{array}$ & $\begin{array}{c}\text { Change, } \\
\text { umole/ } \\
\text { gm }\end{array}$ & $\%$ Change \\
\hline \multicolumn{6}{|l|}{ MA TURE } \\
\hline \multirow[t]{5}{*}{ Sample 1} & fructose & 6.22 & 11.42 & +5.20 & 45.5 \\
\hline & glucose & 6.90 & 15.72 & +8.82 & 56.1 \\
\hline & unknown & 5.87 & 2.96 & -2.91 & 49.6 \\
\hline & inositol & 2.48 & 3.34 & +.86 & 25.7 \\
\hline & sucrose & 312.00 & 262.00 & -50.00 & 16.0 \\
\hline \multirow[t]{5}{*}{ Sample 2} & fructose & 4.18 & 4.62 & +.44 & 9.5 \\
\hline & glucose & 4.00 & 5.72 & $+\quad 1.72$ & 31.1 \\
\hline & unknown & 3.36 & 1.22 & -2.14 & 63.7 \\
\hline & inositol & 1.78 & 1.44 & -.34 & 19.1 \\
\hline & sucrose & 266.00 & 266.00 & 0.00 & 00.0 \\
\hline \multicolumn{6}{|l|}{ INTERMEDIATE } \\
\hline \multirow[t]{5}{*}{ Sample 3} & fructose & 4.38 & 4.76 & .38 & 8.0 \\
\hline & glucose & 3.27 & 3.64 & .37 & 10.2 \\
\hline & unknown & 1.39 & 1.18 & -.21 & 15.1 \\
\hline & inositol & 5.30 & 3.98 & -1.32 & 24.9 \\
\hline & sucrose & 299.00 & 188.00 & -111.00 & 37.1 \\
\hline & & & & & \\
\hline \multirow[t]{5}{*}{ Sample 4} & fructose & 6.24 & 5.36 & .88 & 14.0 \\
\hline & glucose & 3.82 & 5.74 & +1.92 & 33.4 \\
\hline & unknown & 2.36 & 1.08 & -1.28 & 54.2 \\
\hline & inositol & 3.02 & 2.46 & .56 & 18.5 \\
\hline & sucrose & 236.00 & 232.00 & -4.00 & 1.7 \\
\hline
\end{tabular}


glucose; breakdown of amino acids was roughly twice that of the carbohydrates. This fact suggested that these two classes of compounds reacted in a two to one stoichiometric ratio during roasting. However, under the conditions of roasting $\left(210^{\circ} \mathrm{C}\right.$ in a non-aqueous medium) glutamine and glutamic acid can readily self condense to form pyrolidone carboxylic acid (81) and thus may not have reacted in the same manner as other amino acids.

With the thought in mind that the initial concentration of each amino acid controlled the extent to which.it was degraded during roasting (kinetic control), the authors derived an equation which related the concentration of amino acid flavor precursor in the raw peanut with subjectively measured flavor. As a first approximation, based on the evidence, the assumption was made that typical flavor was directly proportional to the concentration of each amino acid flavor precursor, Flavor $\alpha \mathrm{Cp}$, where $\mathrm{Cp}_{\mathrm{p}}$ was the measured flavor precursor concentration in the raw peanut. Since mean preference rank (M) decreased as typical flavor increased (i.e., $M$ was a smaller number for a better tasting sample or Flavor $\alpha \frac{1}{M}$ ) it followed from these proportionalities that another could be written, $\mathrm{C}_{\mathrm{p}} \alpha \frac{1}{\mathrm{M}}$ or $\mathrm{M} \alpha \frac{1}{\mathrm{C}_{\mathrm{p}}}$. Insertion of the constant $\mathrm{K}_{\mathrm{f}}$ (the flavor function constant) into the second proportionality yielded:

$$
M=K_{p} / C_{p}
$$

which was rearranged to give:

$$
\mathrm{K}_{\mathrm{f}}=\mathrm{MCp}
$$

If the assumption that typical flavor was proportional to flavor precursor concentration was justified, the proportionality constant $k_{l}$, for any given precursor in one peanut sample, should be equal within experimental error of determining $M$ and $C p$, to $K_{f}$ for that precursor in any 
other sample regardless of the flavor of the two samples. If, however, the flavor precursor in question produced compounds associated with atypical or off-flavor then $k_{f}$ values for a given precursor in two different samples would not agree since the assumption that typical flavor was proportional to flavor precursor concentration would not be satisfied. These statements would apply only to those samples which were roasted to the same extent. Since the raw/roasted ratio would increase with heaviness of roast and would decrease with lighter roasting, the inclusion of the raw/roasted ratio ( $R$ ) in Equation 2 reduced all samples to an identical heaviness of roast. Division of the right side of Equation 2 by $R$ yielded:

$$
\mathrm{K}_{\mathbf{t}}=\mathrm{MCp} / \mathrm{R}
$$

$\mathrm{K}_{\mathrm{f}}$ values calculated from Equation 3 using the data in Table VI, ratios of $k_{f}$ values, and average $k_{f}$ ratios for the amino acids occurring in peanuts of two maturity classes were determined. The results are tabulated in Table VIII. Ratios near 1.0 indicated those amina acids which contributed to typical flavor; those which departed sharply from 1.0 indicated precursors of atypical or off-flavor. The amino acid concentration data are much more precise by nature than the mean preference rank data. Therefore the agreement of the $k_{f}$ values can be no better than the precision of values for the least precise measurement; namely, the mean preference rank. The arbitrary limits set for average $K_{f}$ values of precursors of typical flavor were $\mathrm{K}_{t}=1.0-1.7 ; \mathrm{K}_{\mathfrak{f}}$ values greater than 2.5 were considered to indicate that the amino acid was a precursor of atypical flavor.

On the basis of these calculations, aspartic acid, asparagineglutamine, glutamic acid, phenylalanine, and histidine were considered 
TABLE VIII

$\mathrm{K}_{\mathrm{f}}$ VALUES, RATIO OF $\mathrm{K}_{\mathrm{f}}$ VALUES, AND AVERAGE RATIOS OF $\mathrm{K}_{\mathrm{f}}$ VALUES IN INTERMEDTATE MATURITY AND FULLY MATURE PEANUTS

\begin{tabular}{|c|c|c|c|c|c|c|c|c|}
\hline \multirow[b]{2}{*}{ Amino Acid } & \multicolumn{3}{|c|}{ Mature } & \multicolumn{3}{|c|}{ Intermediate } & Average & \multirow[b]{2}{*}{ Interpretation } \\
\hline & Sample 1 & Sample 2 & Ratio & Sample 3 & Sample 4 & Ratio & $\begin{array}{c}\text { Ratiot } \\
\text { Std. Deviation } \\
\end{array}$ & \\
\hline Aspartic Acid & 1.6 & 1.4 & 1.1 & 1.6 & 2.1 & 1.3 & $1.2 \pm 0.1$ & $\mathbf{T}$ \\
\hline Threonine & 1.3 & 0.3 & $4 \cdot 3$ & 2.1 & 0.7 & 3.0 & $3.7 \pm 0.7$ & $\mathbf{A}$ \\
\hline Serine & 1.9 & 1.1 & 1.7 & 3.7 & 2.1 & 1.8 & $1.8 \pm 0.1$ & $x$ \\
\hline $\begin{array}{l}\text { Asparagine and } \\
\text { Glutamine }\end{array}$ & 2.9 & 2.1 & 1.4 & 3.7 & 3.5 & 1.1 & $1.3 \pm 0.1$ & $\mathbf{T}$ \\
\hline Proline & 2.6 & 1.4 & 1.9 & 3.1 & 2.4 & 1.3 & $1.6 \pm 0.2$ & $*$ \\
\hline Glutamic Acid & 8.7 & 5.6 & 1.6 & 12.1 & 7.4 & 1.6 & $1.6 \pm 0.0$ & $\mathbf{T}$ \\
\hline Glycine & 2.2 & 1.1 & 2.3 & 4.2 & 1.7 & 2.5 & $2.3 \pm 0.2$ & $\mathrm{x}$ \\
\hline Alanine & 7.1 & 3.2 & 2.2 & 19.5 & 8.1 & 2.4 & $2.3 \pm 0.1$ & $\mathrm{x}$ \\
\hline Valine & 2.2 & 0.7 & 3.1 & 3.7 & 2.1 & 1.8 & $2.5 \pm 0.6$ & * \\
\hline Unknown & 2.9 & 1.1 & 2.6 & 2.6 & 0.7 & 3.7 & $3.2 \pm 0.5$ & $\mathbf{A}$ \\
\hline Isoleucine & 1.3 & 0.7 & 1.9 & 1.5 & 1.1 & 1.5 & $1.7 \pm 0.2$ & $x$ \\
\hline Leucine & 1.0 & 0.4 & 2.5 & 1.6 & 1.1 & 1.5 & $2.0 \pm 0.5$ & * \\
\hline Tyrosine & 1.0 & 0.4 & 2.5 & 1.6 & 0.4 & 4.0 & $3.3 \pm 0.7$ & $\mathbf{A}$ \\
\hline Phenylalanine & 5.8 & 3.9 & 1.5 & 4.8 & 3.5 & 1.4 & $1.5 \pm 0.1$ & $\mathbf{T}$ \\
\hline Lysine & 1.3 & 0.4 & $3 \cdot 3$ & 2.6 & 0.7 & 3.7 & $3.5 \pm 0.2$ & $\mathbf{A}$ \\
\hline Histidine & 0.6 & 0.4 & 1.5 & 1.0 & 0.7 & 1.4 & $1.5 \pm 0.1$ & $\mathbf{T}$ \\
\hline Anmonia & 9.0 & 1.4 & 6.4 & 17.9 & 15.4 & 1.2 & $3.8 \pm 2.6$ & * \\
\hline Arginine & 2.6 & 3.2 & 1.2 & 7.9 & 2.8 & 2.8 & $2.0 \pm 0.8$ & * \\
\hline Tryptophan & 0.6 & 0.7 & 1.2 & 1.5 & 0.7 & 2.3 & $1.8 \pm 0.3$ & $x$ \\
\hline
\end{tabular}

T Precursor of typical flavor

A Precursor of atypical flavor

Intermediate ratio, no prediction
Anomolous ratios 
to be precursors of typical peanut flavor; threonine, the unknown, tyrosine, and lysine were precursors of off-flavor. In Table VIII, precursors of typical flavor were designated as $\mathrm{T}$. whereas precursors of atypical flavor were designated as $A$. A few average $K_{f}$ value ratios in Table VIII were anomolous in that they had large standard deviations and could have been classified as either precursors of typical or atypical flavor. Some of the average $\mathrm{K}_{f}$ values in Table VIII fell between the arbitrary limits set for precursors of typical flavor and precursors of atypical flavor. No predictions were made conerning these amino acids. $K_{f}$ values calculated from Equation 3 and ratios of $K_{f}$ values for immature peanuts are given in Table IX. The ratio of $\mathrm{K}_{\mathrm{f}}$ values indicated that glutamic acid and phenylalanine, as in mature and intermediate maturity peanuts, were precursors of typical roasted peanut flavor. However, the results indicated, in contrast to the results shown in Table VIII for mature and intermediate maturity peanuts, that serine, proline, alanine, valine, leucine, and isoleucine were precursors of typical flavor; asparagine-glutamine and aspartic acid were precursors of atypical flavor.

The differences in interpretation between Tables VIII and IX probably arose from the fact that Sample 5 had a very high mean preference rank $(M=4.0)$. In peanuts of such poor flavor, the mean preference rank must have deviated considerably from.a linear function of roasted peanut flavor. This in turn caused anomolous results in $K_{f}$ values since it was assumed in the derivation of Equation 3 that typical peanut flaincreased in a linear fashion with decreasing mean preference rank.

Equation 3 predicts that $k_{t}$ values for precursors of atypical flavor should be higher in poorer flavored peanuts than the corresponding 
TABLE IX

$K_{f}$ VALUES AND RATIO OF $K_{f}$ VALUES IN IMMATURE PEANUTS

\begin{tabular}{|c|c|c|c|c|}
\hline \multirow[b]{2}{*}{ Amino Acid } & \multicolumn{2}{|c|}{$\mathrm{K}_{\mathrm{f}}$} & \multirow[b]{2}{*}{ Ratio } & \multirow[b]{2}{*}{$\begin{array}{c}\text { Inter- } \\
\text { pretation }\end{array}$} \\
\hline & $\begin{array}{l}\text { Sample } \\
M=4.0\end{array}$ & $\begin{array}{c}\text { Sample } 6 \\
M=3.2\end{array}$ & & \\
\hline Aspartic Acid & 2.08 & 5.25 & 2.52 & A \\
\hline Threonine & 2.08 & 1.05 & 1.98 & $\mathrm{x}$ \\
\hline Serine & 3.76 & 4.20 & 1.12 & $\mathrm{~T}$ \\
\hline $\begin{array}{l}\text { Asparagine and } \\
\text { Glutamine }\end{array}$ & 3.36 & 9.45 & 2.82 & $A$ \\
\hline Proline & 4.60 & 5.63 & 1.22 & $\mathrm{~T}$ \\
\hline Glutamic Acid & 10.00 & 14.33 & 1.43 & $\mathrm{~T}$ \\
\hline Glycine & 6.70 & 2.46 & 2.72 & $A$ \\
\hline Alanine & 19.70 & 13.00 & 1.52 & $\mathrm{~T}$ \\
\hline Valine & 3.76 & 3.84 & 1.02 & $\mathrm{~T}$ \\
\hline Isoleucine & 1.68 & 1.76 & 1.05 & $\mathrm{~T}$ \\
\hline Leucine & 1.68 & 1.76 & 1.05 & $\mathrm{~T}$ \\
\hline Tyrosine & 1.68 & $-\cdots$ & --- & - \\
\hline Phenyla lanine & 4.20 & 5.60 & 1.33 & $\mathrm{~T}$ \\
\hline
\end{tabular}


value in good flavored peanuts since for a given $M, C p$ should be higher in poorer flavored peanuts. Table VIII shows that $K_{\S}$ values for threonine, the unknown, tyrosine, and lysine were indeed higher in peanuts which had poorer flavor. The fact that in very immature peanuts, which have a very high level of off-flavor, the amino acids which were predicted to be precursors of atypical flavor occur at very high concentrations, tends to support the conclusions drawn from $\mathrm{K}_{\mathrm{f}}$ values concerning precursors of atypical flavor.

Similarly, the amino acids which contributed to typical peanut flavor according to calculation of $\mathrm{k}_{\mathrm{f}}$ values were the same ones which made up about $50 \%$ of the total free amino acids in the fully mature peanuts.

\section{Changes in Carbohydrates During Roasting}

The data in Table VII showed that sucrose underwent only small decreases in concentration during roasting of peanuts having good flavor (Samples 2 and 4). The results might have been interpreted to mean that sucrose per se was not involved in the production of flavor. This interpretation agreed with the results of El'ode et al. (82) who showed that sucrose was much less reactive in the browning reaction than monosaccharides.

Glucose and fructose must have been consumed during roasting since the increase in concentration of these sugars was less than the amount which could have been produced from the hydrolysis of sucrose.

Evidently, fructose was utilized in the reactions to produce volatile compounds to a greater extent than glucose since the increase in fructose concentration during roasting of peanuts was less than that of glucose. This result was reasonable in light of the work of 
Casey et al. (74) who showed that fructose exhibited much higher rates of production of volatiles than glucose in model hexose-amino acid sys tems.

Monosaccharides are extremely important in the formation of pyrazine compounds which have been implicated as the character impact compounds of roasted peanuts (7). Wiggins (58) observed that ammonia heated with an acid hydrolyzed (inverted sucrose) sample of molasses gave a variety of pyrazine compounds; unhydrolyzed molasses took up only about one-half as much ammonia. Evidence discussed in Chapter VI with model glucose-amino acid systems showed that qualitatively the same volatile pyrazine compounds were produced regardless of the amino acid employed as the nitrogen source.

Hypothetical Mechanism for the Conversion of Amino Acids and Carbohydrates to Volatile Compounds

Consideration of the results obtained in this work led the authors' to postulate a plausible mechanism, shown in Figure 5, for the conversion of amino acids and sugars to volatile compounds associated with peanut flavor. The mechanism, which includes ideas set forth by Hodge $(37,46)$ and Rohan and Stewart (21), involves the initial addition of an amino acid to the anomeric carbon atom of an aldose followed by dehydration to the 1,2-eneaminol (I) and elimination of hydroxyl ion to give the Schiff base cation (II). The Schiff base cation can undergo hydrolysis to an $\alpha$-dicarbonyl compound (III) which is converted to browning pigments by a series of steps. Alternatively, the Schiff base cation (II) could decarboxylate to the imine (IV) which would rapidly hydrolyze to yield an aldehyde and a dieneamine (V). Enolization of the 1,2 double bond and migration of the 3,4 double bond yields the unsaturated 


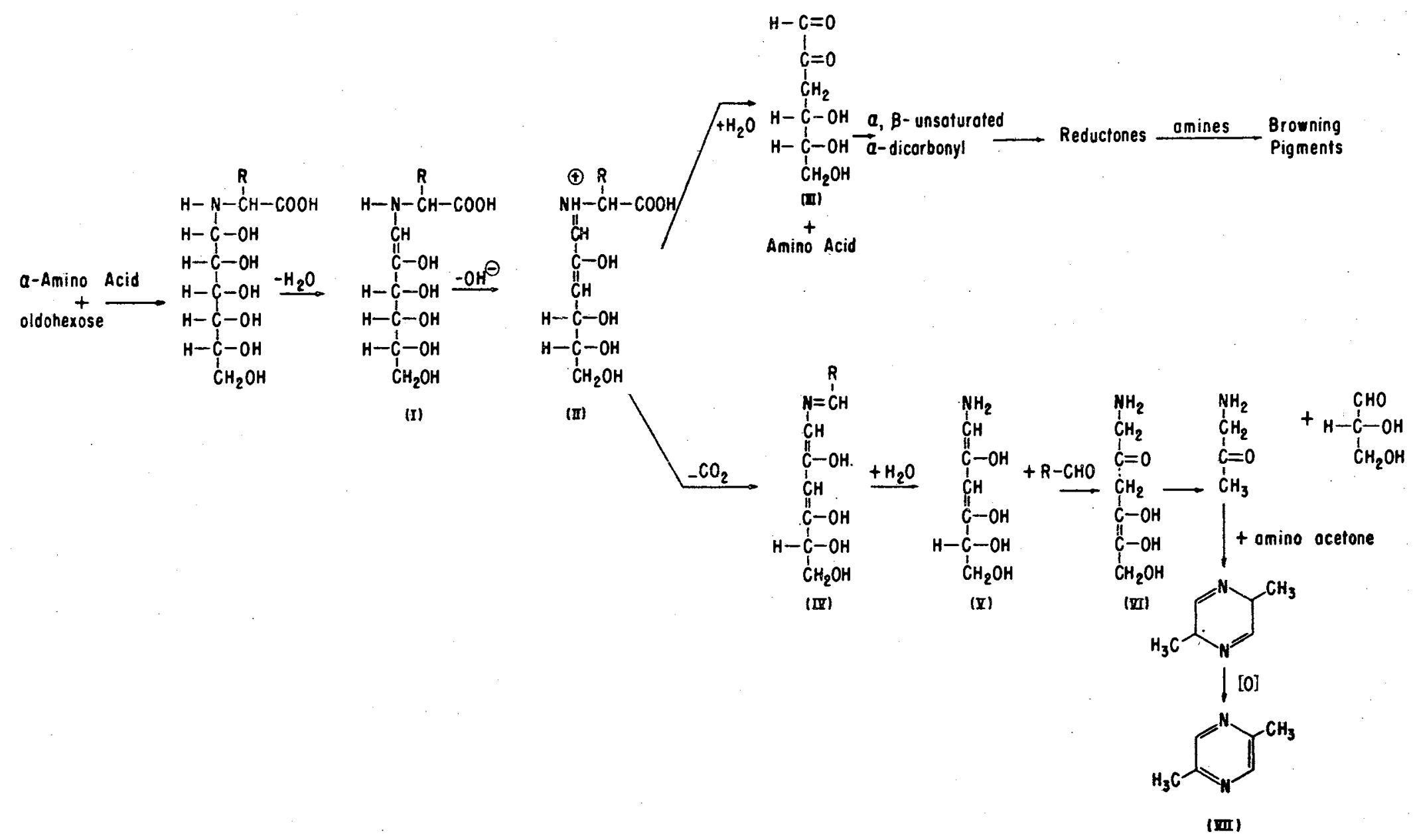

Figure 5. A Postulated Mechanism for the Conversion of Amino Acids and Sugars to Volatile Compounds 
ketoamine (VI). This compound then could undergo retro-aldol condensation to yield amino acetone and glyceraldehyde. Condensation of two molecules of amino acetone yields 2,5-dimethylpyrazine (VII) which was one of the major pyrazine compounds found in roasted peanuts $(13,75)$. 
CHAPTER V

PRODUCTION OF PRECURSORS OF TYPICAL AND ATYPICAL

PEANUT FLAVOR IN MATURING PEANUTS

\section{Introduction}

Immature peanuts, even when correctly cured, possess a high level of off-flavor. It was suggested in Chapter IV that amino acids and carbohydrates are the precursors of the compounds that give roasted peanuts their flavor. Further, it was suggested that aspartic acid, glutamic acid, glutamine-asparagine, histidine, and phenylalanine were the precursors of typical peanut flavor; threonine, tyrosine, lysine, and an unknown amino acid were considered to be precursors of atypical flavor. If the previous suggestions that certain amino acids are required for the production of typical peanut flavor while others produce atypical- or off-flavor are true, then one would expect that one or both of two events would occur: Precursors of typical peanut flavor would increase in concentration during maturation or precursors of atypical flavor would decrease in concentration as maturity was approached.

\section{Procedure}

Collection of Samples

Argentine-Spanish peanuts, which were planted on the same date and grown in pots in a plant growth chamber in a randomized block design were harvested periodically by removing two pots (replicates) from each block. During the maturation of the plant, pegs were dated at the time 
of their appearance and at each harvest date the peanuts were divided into three groups. Peanuts in group A were those whose pegs appeared earliest of those harvested; group $B$ represented peanuts of intermediate age and group $\mathrm{C}$ contained peanuts harvested from the most recent pegs. Therefore in group $\mathrm{A}$. were peanuts having a long growing season and group $C$ peanuts were those having the shortest growing season. In addition, peanuts within each harvest date were classified as mature, intermediate in maturity, or immature according to external seed characteristics as described in the section of Chapter IV entitled "Determination of Peanut Maturity."

Extraction and Determination of Individual Amino Acids and Carbohydrates

Flavor precursors were extracted and estimated using procedures outlined in Chapter IV in the sections entitled "Preparation of Peanuts for NaCl or Perchloric Acid Extraction," "Perchloric Acid Extraction,"

"Preparation of Samples for Carbohydrate Analysis," "Gas Chromatography of Trimethylsilyl Ethers," and "Amino Acid Analyses."

\section{Results and Discussion}

In a preliminary experiment, the replicates from each harvest date from the mature peanuts of group A were combined and in like manner, the immature peanuts from each harvest date of group $\mathbf{C}$ were combined.

Amino acid analyses were performed on these samples as described in the "Procedure" section of this chapter. The concentration of individual amino acids in these samples is presented in Table $X$. Proline and serine values from group $C$ harvest $7 / 2 / 66$ were not calculated due to malfunction of the amino acid analyzer. There were no group A peanuts available from the $5 / 8 / 66$ harvest date (i.e., there were no peanuts 


\section{TABLE X}

AMINO ACID CONTENT (HMOLES/GM FAT-FREE MEAL) OF PEANUTS CLASSIFIED INTO THREE GROUPS ACCORDING TO AGE WITHIN HARVEST DATE

\begin{tabular}{|c|c|c|c|c|c|c|}
\hline \multirow[b]{2}{*}{ Harvest Date } & \multicolumn{6}{|c|}{ Oldest (Group A) } \\
\hline & $6 / 5$ & $6 / 11$ & $6 / 11$ & $6 \longdiv { 2 5 }$ & $7 / 2$ & $7 / 9$ \\
\hline Sample No. & 2 & 3 & 4 & 5 & 6 & 7 \\
\hline Aspart1c & 1.65 & 1.54 & 1.78 & 1.58 & 1.98 & 1.39 \\
\hline Threonline & 0.24 & 0.24 & 0.40 & 0.40 & 0.40 & 0.40 \\
\hline Serine & 0.71 & 1.09 & 0.99 & 0.79 & 0.99 & 0.40 \\
\hline $\begin{array}{l}\text { Aoperagl ne and } \\
\text { Glutensine }\end{array}$ & 4.73 & 3.33 & 2.38 & 2.18 & 3.37 & 2.18 \\
\hline Proline & 1.18 & 2.61 & 0.79 & 0.40 & 0.59 & - \\
\hline Glutamlc & 11.58 & 3.92 & 1.58 & 1.58 & 20.59 & 13.66 \\
\hline Glycine & 0.71 & 0.95 & 0.79 & 0.99 & 0.79 & 0.59 \\
\hline Alanine & 1.42 & 1.43 & 1.19 & 1.19 & $\therefore 1.39$ & 1.19 \\
\hline Vellne & 0.71 & 0.83 & 0.59 & 0.59 & 0.79 & 0.59 \\
\hline Balf-Cystine" & 3.31 & 3.92 & 8.12 & 9.90 & 14.45 & 9.90 \\
\hline Isoleucine & 0.24 & 0.36 & 0.40 & 0.40 & 0.59 & 0.40 \\
\hline Leucine & 0.47 & 0.36 & 0.20 & 0.20 & 0.20 & 0.20 \\
\hline Iyrosine & 0.05 & 0.12 & trece & 0.20 & 0.20 & 0.20 \\
\hline Phenylalenine & 0.71 & 0.83 & 2.77 & 3.76 & 5.35 & 2.57 \\
\hline Lysine & 0.30 & 0.14 & 0.17 & 0.25 & 0.20 & 0.20 \\
\hline Histidine & $0 . \infty 2$ & 0.07 & 0.14 & 0.12 & 0.25 & 0.20 \\
\hline Amonala & 0.89 & 0.71 & 3.11 & 1.49 & 1.73 & 7.92 \\
\hline Arginine & 1.18 & 0.48 & 0.45 & 0.50 & 0.50 & 0.59 \\
\hline
\end{tabular}

\begin{tabular}{|c|c|c|c|}
\hline $5 / 28$ & $\frac{\text { Younges }}{6 / 4}$ & $\frac{\text { roup } c)}{6 / 11}$ & $7 / 2$ \\
\hline 1 & 2 & 3 & 6 \\
\hline 2.48 & 4.05 & 1.44 & 8. 89 \\
\hline 0.88 & 1.19 & 0.67 & 2.37 \\
\hline 0.73 & 1.19 & 0.58 & $=$ \\
\hline 6.72 & 10.48 & 7.40 & 11.66 \\
\hline 2.19 & 1.90 & 2.79 & - \\
\hline 8.47 & 16.43 & 3.75 & 26.48 \\
\hline 0.58 & 0.71 & 0.38 & 1.98 \\
\hline 2.04 & 2.86 & 1.44 & 5.34 \\
\hline 0.44 & 0.71 & 0.29 & 1.19 \\
\hline $2: 34$ & 4.29 & 0.77 & 5.73 \\
\hline 0.15 & 0.24 & 0.10 & 0.59 \\
\hline 0.29 & 0.24 & 0.10 & 0.59 \\
\hline 0.15 & 0.14 & 0.06 & 0.20 \\
\hline 0.29 & 0.71 & 0.29 & 1.19 \\
\hline 1.75 & 1.67 & 3.63 & 2.47 \\
\hline 0.44 & 0.71 & 0.42 & 0.74 \\
\hline 0.73 & 0.95 & 0.42 & 0.74 \\
\hline 21.46 & 18.33 & 12.08 & 33.33 \\
\hline
\end{tabular}

* Recently found not to be cysteine 
having mature seed characteristics in this early harvest date.)

Certain conclusions of considerable interest were drawn from the data. First, in group $A$, the concentration of aspartic acid, glutamic acid, glutamine-asparagine, phenylalanine and histidine (i.e., the amino acids implicated in the production of typical peanut flavor in Chapter IV) either remained relatively constant or tended to increase with age. Next, the concentration of threonine, tyrosine, and lysine (amino acids implicated in the production of atypical peanut flavor in Chapter IV) remained relatively constant or decreased with age. The unknown amino acid which was thought to be a precursor of atypical flavor increased significantly with age however. When the data of Table $X$ were plotted (harvest date vs. amino acid concentration) a large amount of scattering of points was observed. This was attributed to sampling error and the inability of personnel to separate nature and immature nuts on the basis of seed characteristics alone.

In an effort to minimize sampling error, the replicates of group B (peanuts of intermediate age) from each harvest date were combined. These samples contained peanuts of al1 maturity groups on the basis of seed characteristics. Table XII gives percent by weight of the various maturity groups within group B. Samples from the early harvest date contained more immaturity than samples from later harvest dates which was expected.

Table XI gives amino acid contents in peanuts from various harvest dates; Figure 6 shows the same information in graphic form. Apparently sampling error was still prevalent but the conclusions drawn in Table XI and Figure 6. were the same as those drawn from analyses of the older and younger peanuts (Table $X)$. An interesting point brought out by the data 


\section{TABLE XI}

SYNTHESIS OF AMINO ACID FLAVOR PRECURSORS--AMINO ACID CONTENT (HMOLES/GM FAT-FREE MEAL) OF INTERMEDIATE AGE PEANUTS FROM EACH HARVEST DATE

\begin{tabular}{lccccccc} 
Harvest Date & $5 / 28$ & $6 / 4$ & $6 / 11$ & $6 / 18$ & $6 / 25$ & $7 / 2$ & $7 / 9$ \\
Sample Number & 1 & 2 & 3 & 4 & 5 & 6 & 7 \\
\hline & & & & & & & \\
Aspartic Acid & 4.5 & 1.9 & 1.8 & 1.1 & 0.8 & 1.9 & 0.8 \\
Threonine & 0.8 & 0.3 & 0.5 & 0.2 & 0.2 & 0.3 & 0.1 \\
Serine & 0.8 & 0.5 & 0.7 & 0.3 & 0.2 & 0.3 & 0.2 \\
Asparagine + Glutamine & 7.2 & 3.4 & 3.9 & 2.1 & 1.2 & 2.5 & 1.1 \\
Proline & 2.3 & 0.9 & 1.5 & 0.8 & 0.6 & 1.0 & 0.4 \\
Glutamic Acid & 15.3 & 9.8 & 12.4 & 10.4 & 6.8 & 15.8 & 8.7 \\
Glycine & 1.1 & 0.4 & 0.9 & 0.5 & 0.4 & 0.7 & 0.5 \\
Alanine & 3.4 & 1.5 & 1.8 & 1.0 & 0.7 & 1.6 & 0.7 \\
Valine & 0.9 & 0.5 & 0.9 & 0.6 & 0.4 & 0.7 & 0.4 \\
Unknown & 2.5 & 2.4 & - & 4.4 & 3.1 & 7.1 & 5.3 \\
Isoleucine & 0.2 & 0.1 & 0.3 & 0.3 & 0.2 & 0.3 & 0.2 \\
Leucine & 0.4 & 0.2 & 0.3 & 0.2 & 0.1 & 0.2 & 0.2 \\
Tyrosine & 0.1 & 0.1 & 0.2 & 0.1 & 0.1 & 0.1 & 0.1 \\
Phenylalanine & 0.6 & 0.4 & 0.9 & 1.5 & 0.9 & 2.0 & 1.2 \\
Lysine & 1.4 & 0.6 & - & 0.3 & 0.3 & 0.2 & 0.2 \\
Histidine & 0.5 & 0.2 & - & 0.2 & 0.2 & 0.2 & 0.2 \\
Amonia & 1.1 & 4.2 & - & 1.4 & 0.9 & 0.7 & 0.6 \\
Arginine & 16.4 & 5.5 &.- & 3.8 & 4.6 & 2.7 & 1.1
\end{tabular}




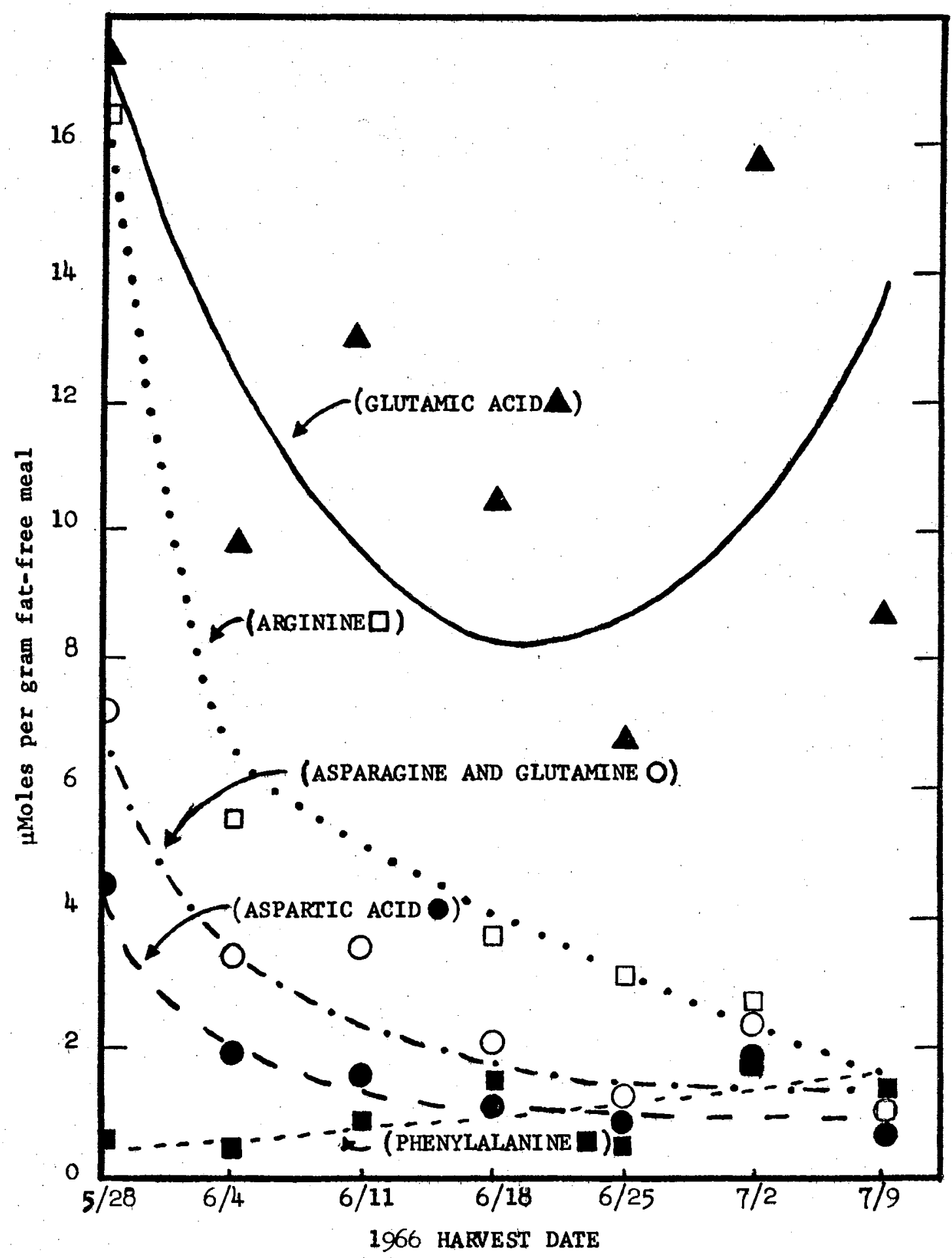

Figure 6. Amino Acid Concentration in Intermediate Age Peanuts as a Function of Harvest Date 
in Figure 6 was the sharp drop in glutamic acid concentration near the middle of the growing season followed by a sharp increase during the latter stages of the growing season. This observation may be significant in view of results presented in Chapter VI which show that the major portion of volatile pyrazine compounds in roasted peanuts probably arise from glutamic acid.

The data of Figure 6 and Tables $X$ and $X I$ also indicated that the difference in arginine concentration between immature and mature peanuts was on the order of 20 to 40 fold showing that a chemical measurement of arginine content holds some promise as a sensitive method for the evaluation of immaturity in certain lots of peanuts.

Carbohydrate concentrations in the peanut samples used for the amino acid analyses given in Table XI and Figure 6 were determined as described in the "Procedures" section of this chapter. The results, which are given in Table XII and Figure 7, were not as dramatic as those of the amino acid analyses but certain conclusions could be drawn. Total sugars decreased with peanut age but increased rather sharply at the latter stages of development. This trend was due largely to changes in sucrose concentration, but fructose seemed to follow the same trend. Glucose concentration dropped off and then rose slightly at later harvest dates; inositol concentration tended to decrease with age.

Percent immaturity by weight was determined in these peanuts before analysis (Table XII) so that any variation in maturity might be accounted for in interpreting the results. Sample 6 contained a higher percentage of immature and intermediate maturity peanuts which probably accounted for values for amino acid and carbohydrate concentrations which were out-of-line with surrounding values (Figure 6 and Table XII). 


\section{TABLE XII}

SYNTHESIS OF CARBOHYDRATE FLAVOR PRECURSORS--SUGAR CONTENT OF FAT-FREE MEAL FROM INTERMEDIATE AGE PEANUTS FROM EACH HARVEST DATE

\begin{tabular}{|c|c|c|c|c|c|c|c|c|c|c|c|}
\hline \multirow[b]{2}{*}{ Sample No. } & \multicolumn{2}{|c|}{ Harvest Date } & \multicolumn{5}{|c|}{ Moles/gm fat-frec Meal } & \multicolumn{4}{|c|}{ Percent by Welght } \\
\hline & Month & Day & Pructose & Glucose & Inositol & Sucrose & Total & Mature & Intermediate & $\begin{array}{c}\text { Mature }+ \\
\text { Intermediate }\end{array}$ & Immature \\
\hline 1 & 5 & 28 & 7.0 & 6.8 & 6.0 & 328.3 & 348.1 & 33 & 36 & 69 & 31 \\
\hline 2 & 6 & 4 & 9.3 & 5.9 & 4.7 & 301.6 & 321.5 & 54 & 34 & 88 & 12 \\
\hline 3 & 6 & 11 & 4.3 & 3.8 & 3.4 & 293.6 & 305.1 & 63 & 26 & 89 & 11 \\
\hline 4 & 6 & 18 & 3.4 & 3.8 & 2.3 & 250.9 & 260.4 & 43 & 46 & 89 & 11 \\
\hline 5 & 6 & 25 & 7.1 & 4.4 & 2.9 & 206.0 & 220.4 & 50 & 38 & 88 & 11 \\
\hline 6 & 7 & 2 & 10.1 & 7.3 & 5.0 & 308.9 & 331.3 & 29 & 56 & 85 & 15 \\
\hline 7 & 7 & 9. & 7.8 & 4.3 & 2.1 & 284.0 & 298.3 & 45 & 45 & 90 & 10 \\
\hline
\end{tabular}




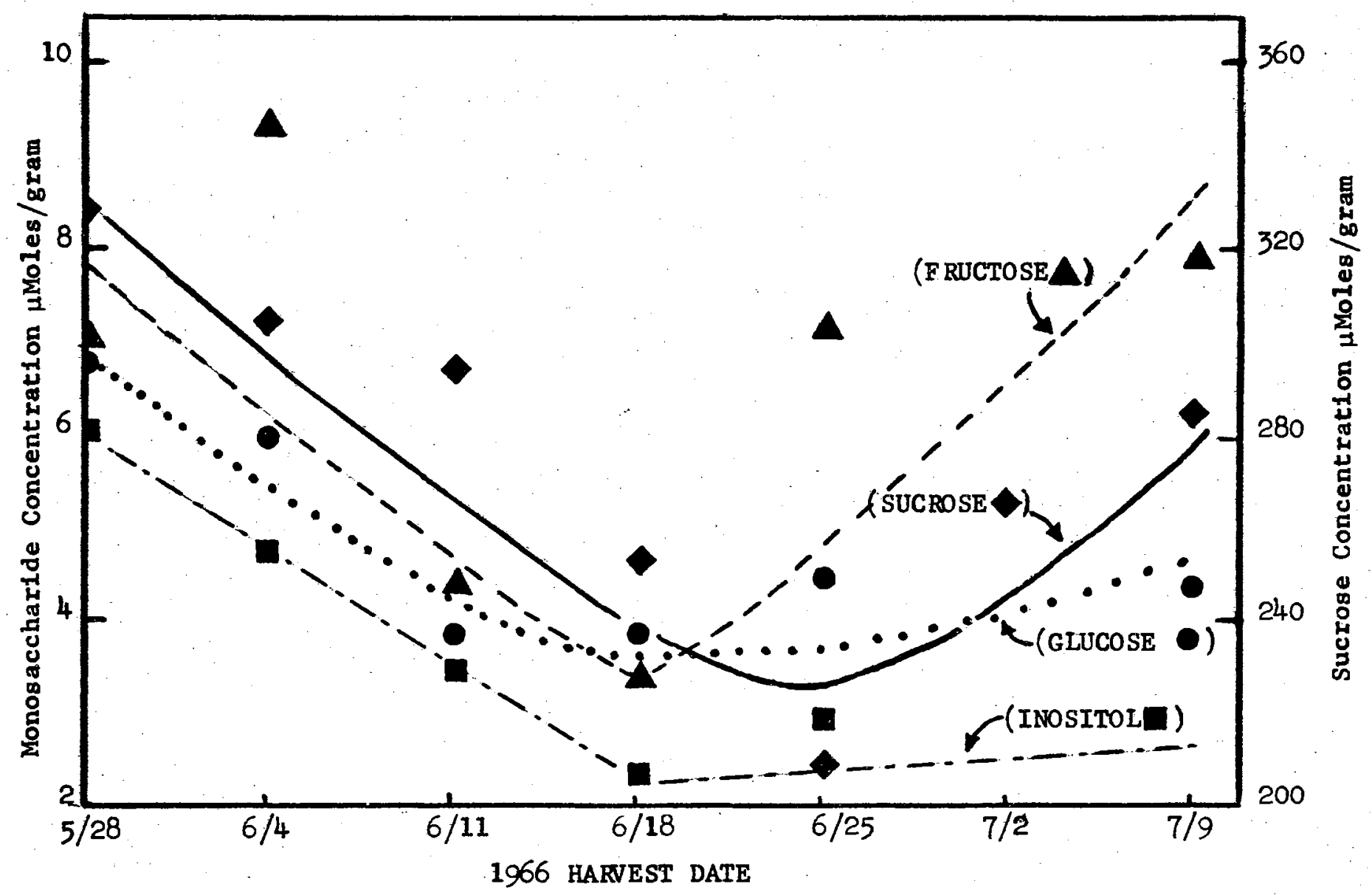

Figure 7. Carbohydrate Concentration in Intermediate Age Peanuts as a Function of Harvest Date 
Since immature peanuts have poorer flavor than mature ones, one would predict that precursors of typical peanut flavor would increase in concentration during maturation or that precursors of atypical flavor would decrease in concentration during the same period or that both events would occur.

The results presented in this chapter indicated that both events occurred during maturation of peanuts. The only exception was that the concentration of the unknown amino acid increased in concentration with. increasing age whereas its concentration was predicted to decrease with age. 
CHAPTER VI

\section{FORMATION OF PYRAZINE COMPOUNDS}

\section{IN MODEL SUGAR-AMINE SYSTEMS}

\section{Introduction}

Mason et a1. (13) showed that a number of simple alkylated pyrazines were contained in the volatile compounds obtained by high vacuum outgassing of roasted peanuts. This group suggested that some of these pyrazine compounds were responsible for the roasted-nutty aroma of roasted peanuts. Deck and Chang (16) isolated 2,5-dimethylpyrazine from potato chips; Reichstein and Staudinger (28) and Goldman et a1. (29) found pyrazines in roasted coffee. It was suggested in Chapter III that roasted cocoa beans might also contain pyrazine compounds.

In Chapter IV it was proposed that amino acids and carbohydrates were the precursors of volatile compounds responsible for the typical flavor of roasted peanuts. Since this was suggested, it was important to demonstrate that the peanut flavor precursors (amino acids and sugars) çould give rise to peanut flavor compounds (pyrazines).

The work of Etard (52), Stoehr (53), Brandes and Stoehr (55), Stolte (56), Tanret (57), Wiggins (58), Hough et al. (60), Hurd (63) and Dawes and Edwards (30) demonstrated that pyrazines were indeed formed in heated aqueous carbohydrate-amine or carbohydrate-ammonium ion systems. The preceding references were discussed in greater detail in Chapter II. 
The early work concerning the formation of pyrazine compounds was carried out in aqueous model systems which were not a good representation of a peanut-like situation.

The objectives of work presented in this chapter were to develop a model sugar-amino acid system which was more peanut-like than the aqueous ones used by earlier workers, to demonstrate the formation of peanut flavor components in this system and to try to gain some insight into the mechanism of formation of pyrazine compounds in amino acid. carbohydrate systems of low water content. A further objective was to show that a model system containing a mixture of carbohydrates and amino acids qualitatively and quantitatively like that of peanuts could give the same distribution of volatile pyrazine compounds as that produced during normal roasting of peanuts.

\section{Procedure}

Materials--DL-aspartic acid (A grade), L-glutamine (A grade) and D-asparagine hydrate were obtained from Calbiochem, Los Angeles, California; DL-glutamic acid- $\mathrm{H}_{2} \mathrm{O}$ and DL-phenylalanine were purchased from Nutritional Biochemicals Corporation, Cleveland, Ohio; diethylene glycol (histologica1) and sucrose were purchased from Fisher Chemical Company, Fair Lawn, New Jersey; D-glucose (A.R.) was obtained from the Mallinckrodt Chemical Company, St. Louis, Missouri; fructose (C.P.) was a product of Pfanstiehl Laboratories, Inc., Waukegan, Illinois; and methylene chloride was purchased from the Aldrich Chemical Company, Milwaukee, Wisconsin. Pyrazine, 2-methylpyrazine, 2,5-dimethylpyrazine, 2-methy 1-6-ethylpyrazine, 2-n-pentylpyrazine, and 2-methy 1-5-n-penty1pyrazine were gifts from the Wyandotte Chemicals Corporation, Wyandotte, Michigan. Trime thylpyrazine, 2,6-dime thy1-3-ethylpyrazine, and 
2,5-dimethyl-3-ethylpyrazine were synthesized by alkylation of corresponding dimethyl compounds with ethyl lithium or methyl 1ithium. The last three compounds were synthesized by Mr. Philip Koehler in our laboratory. The Thermocap relay was a product of the Niagra Electron Laboratories, Andover, New York.

Methods--Model systems were routinely prepared by dissolving 10 moles each of the carbohydrate and amino acid in $20 \mathrm{ml}$ of deionized water. The water solution of the reactants was transferred to $200 \mathrm{ml}$ of diethylene glycol maintained at $120-123^{\circ} \mathrm{C}$ in a $250 \mathrm{ml}$ round bottomed flask immersed in a mineral oil bath. The temperature of the mineral oil bath was maintained with a Thermocap relay connected to a 1000 watt immersion heater; both the oil bath and the reaction mixture were stirred with a magnetic stirrer.

After heating had continued for 26 hours, the reaction mixture was transferred to a $250 \mathrm{ml}$ separatory funnel connected to the inlet of a falling film evaporator. The falling film evaporator used in these studies was similar to that described by Herz and Chang (83) except that volatiles were trapped in a single cold finger trap at $-196^{\circ} \mathrm{C}$, the column was heated to $98^{\circ} \mathrm{C}$, and the sample was introduced onto the column from a separatory funnel. A smaller trap was placed between the vacuum pump and the larger trap to prevent volatile material from the vacuum or oil diffusion pumps from contaminating the volatiles produced during heating of the reaction mixture. The material obtained after heating the reaction mixture was passed over the evaporator three times at a rate of about $400 \mathrm{ml}$ per hour to remove volatiles as completely as possible. The material collected in the large cold finger trap was transferred under vacuum to a detachable $100 \mathrm{ml}$ flask connected to the 
bottom of the cold finger trap by evaporating the liquid nitrogen in the trap with a stream of air. After the liquid nitrogen had evaporated, warm water was poured into the cold finger trap to cause the material contained in it to drop to the liquid nitrogen cooled $100 \mathrm{ml}$ flask attached to the cold finger trap. After the transfer was complete, the small flask was removed from the cold finger trap and stored at $-20^{\circ} \mathrm{C}$ prior to further steps.

The collected material was allowed to warm to room temperature after which ultraviolet spectra were obtained on appropriate water dilutions of the falling film distillate. The material from the trap was extracted 5 times with $5 \mathrm{~m} 1$ portions of redistilled methylene chloride. The combined methylene chloride extracts were dried over 2 gm of sodium sulfate after which the extract was reduced to a small volume by rotary evaporation. The evaporated extract was transferred quantitatively to a $3 \mathrm{ml}$ volumetric flask and the contents were made up to volume with redistilled methylene chloride. Aliquots of this material were analyzed by gas 1iquid chromatography on a Perkin-Elmer Model 801 dual hydrogen flame gas chromatograph using the following conditions: Column--20 ft $x \frac{1}{4}$ inch o.d. glass column containing $15 \%$ w/w Carbowax $20-M$ on Gas Chrom Q; flow rate--48 $\mathrm{ml}$ per minute of nitrogen; temperature--1inear program from $75-190^{\circ} \mathrm{C}$ at $4^{\circ} \mathrm{C}$ per minute, injector temperature $220^{\circ} \mathrm{C}$. Gas chromatographic peaks were quantitated by comparison of peak areas from samples with those of known weights of standards chromatographed the same day under the same conditions. Duplicate analyses of the standard and samples were conducted and the results averaged to obtain the data presented in this chapter.

A prototype of the LKB 9000 combination mass spectrometer-gas 
chromatograph (MS-GLC) was used for mass spectral investigations. The conditions were as follows: Column and conditions--24 $\mathrm{ft} \times \frac{1}{4}$ inch o.d. glass column containing 5\% w/w Carbowax $20-\mathrm{M}$ on Gas Chrom Q operated isothermally at $120^{\circ} \mathrm{C}$ at a helium flow rate of $40 \mathrm{ml}$ per minute; mass spectrometer--electron energy $70 \mathrm{ev,} \mathrm{trap} \mathrm{current} 38$ Hamps, accelerating voltage $3.5 \mathrm{kv}$, multiplier voltage $2.1 \mathrm{kv}$, filter $120 \mathrm{cps}$, and molecule separator temperature $280^{\circ} \mathrm{C}$.

\section{Results and Discussion}

A mixture containing about 0.21 gm of 2,5-dimethylpyrazine in $50 \mathrm{ml}$ of diethylene glycol, was passed over the falling film evaporator. Quantitative ultraviolet spectra were taken on the material which did not distill to the cold finger trap. The results showed that $95.1 \%$ of the original absorbancy was removed after one pass over the evaporator; $99.3 \%$ after two passes.

A solution of $10 \mu 1$ of 2-methylpyrazine and $10 \mu 1$ of 2-n-penty1pyrazine in $50 \mathrm{ml}$ of water was prepared. Sixteen $\mathrm{ml}$ aliquots of this solution were placed into separatory funnels and each aliquot was extracted 3 times with $5 \mathrm{ml}$ of $\mathrm{n}$-pentane, diethyl ether, or methylene chloride. It was found that after the third extraction about $4 \%$ of the original absorbancy remained in the aqueous layer when extraction was carried out with methylene chloride while diethyl ether or n-pentane failed to extract $26 \%$ and $61 \%$ of the original absorbancy respectively.

Diethylene glycol (100 ml) was heated with 50 mMoles of ammonium hydroxide in water for 30 hours at $120^{\circ} \mathrm{C}$. The material was passed over the falling film evaporator three times, extracted with methylene chloride and subjected to gas-liquid chromatography as described in the "Procedure" section of this chapter. No pyrazine compounds were 
detected by ultraviolet spectrometry of the falling film distillate or by gas chromatography of methylene chloride extracts of the distillate.

A standard solution containing pyrazine, 2-methylpyrazine, and 2,5dimethylpyrazine in $25 \mathrm{ml}$ of methylene chloride was subjected to rotary evaporation as described in the "procedure" section of this chapter. Gas-liquid chromatograms of the solution were obtained before and after evaporation. It was found that about $83 \%$ of the pyrazine was recovered after evaporation; $92 \%$ and $96 \%$ of 2 -methylpyrazine and 2,5-dimethylpyrazine respectively were recovered.

This work showed that the solvent (diethylene glycol) when heated with a nitrogen source produced no pyrazine compounds and that pyrazine compounds (except pyrazine itself) which were produced in the sugar amino acid model systems could be recovered from the diethylene glycol reaction medium in nearly quantitative yield.

The retention times of compounds producted in the model systems were compared with standards run under the same conditions. Retention times relative to that of 2 -methylpyrazine were also calculated for each significant peak derived from the model systems (Table XIII). Equality af a relative retention time of a sample peak with that of a standard one was routinely used for the identification of peaks from the various model systems. Mass spectra of peaks from the asparagine-glucose model system were identical with standards having the same relative retention time. This fact indicated that it was valid to identify peaks from the model systems on the basis of their relative retention times.

Table XIV shows the total yield of pyrazine compounds (measured by total ultraviolet absorbancy at the absorption maximum in the aqueous falling film distillates) from several of the model systems studied. 
TABLE XIII

RETENTION TIMES AND RETENTION TTMES RELATIVE

TO 2-METHYLPYRAZINE OF GAS CHROMATOGRAPHIC

PEAKS FROM THE ASPARAGINE-GLUCOSE

MODEL SYSTEM

\begin{tabular}{lcccc}
\hline \multicolumn{1}{c}{ COMPOUND } & \multicolumn{1}{c}{ MODEL SYSTEM } & \multicolumn{2}{c}{ STANDARD } \\
& $\begin{array}{l}\text { Retention } \\
\text { Time (min) }\end{array}$ & $\begin{array}{c}\text { Relative } \\
\text { Retention }\end{array}$ & $\begin{array}{c}\text { Retention } \\
\text { Time (min) }\end{array}$ & $\begin{array}{c}\text { Relative } \\
\text { Retention }\end{array}$ \\
\hline pyrazine & 13.65 & 0.88 & 13.65 & 0.88 \\
2-methylpyrazine & 15.50 & 1.00 & 15.55 & 1.00 \\
2,5-dimethylpyrazine & 17.60 & 1.14 & 17.55 & 1.13 \\
2-methyl-6-ethylpyrazine & 19.70 & 1.28 & 19.70 & 1.27 \\
trimethylpyrazine & 20.30 & 1.31 & 20.30 & 1.31 \\
2,5-dimethy1-3-ethylpyrazine & 21.55 & 1.39 & 21.60 & 1.39 \\
2,6-dimethyl-3-ethylpyrazine & 22.20 & 1.43 & 22.20 & 1.43 \\
2-n-pentylpyrazine & 27.70 & 1.79 & 27.70 & 1.78 \\
2-methyl-5-n-pentylpyrazine & 29.90 & 1.93 & 29.50 & 1.90 \\
\hline
\end{tabular}


TABLE XIV

TOTAL YIELD OF PYRAZINES PRODUCED FROM HEATED SUGAR-AMINO ACID OR SUGAR AMMONIUM CHLORIDE MODEL SYSTEMS

\begin{tabular}{lcc}
\hline MODEL SYSTEM & $\begin{array}{c}\text { TOTAL YIELD } \\
\text { (NMoles) }\end{array}$ & $\begin{array}{c}\text { ABSORPTION } \\
\text { MAXIMUM (mul) }\end{array}$ \\
\hline Asparagine-glucose & 411 & 272 \\
Glutamine-glucose & 205 & 272 \\
Aspartic acid-glucose & 198 & 274 \\
Glutamic acid-glucose & 114 & 274 \\
$\mathrm{NH}_{4}$ Cl-glucose & 59 & 262 \\
$\mathrm{NH}_{4}$ Cl-fructose & 195 & 280 \\
Asparagine-sucrose & 268 & 274 \\
Asparagine-glucose- & 11643 & 280 \\
acetaldehyde & & \\
\hline
\end{tabular}


The results indicated that the absorption maximum was near that expected for a mixture of pyrazines $(\lambda \max 2$-methylpyrazine $=278 \mathrm{~m} \mu)$. Asparagine gave the highest yields of pyrazines when heated with glucose; glutamic acid the lowest. The table also shows that the yield for aspartic acid is nearly one-half that of asparagine suggesting that both nitrogens of asparagine were incorporated into pyrazines. The same was true when the glutamine-glucose system was compared with the glutamic acid-glucose system. The overall yield of pyrazines in the asparagineglucose system was about $4 \%$ on the basis of 10 mMoles of glucose used as a reactant; the yield from glutamic acid and glucose was about $1 \%$.

One mechanism which could be postulated for the formation of pyrazines involves the addition of ammonia, produced from the amino acid, to sugar degradation products to give reactive compounds, such as $\alpha$-amino carbonyl compounds, which could form pyrazines readily (Chapter II). Another possible mechanism involves the initial rate limiting nucleophylic attack of the amino acid nitrogen on the carbonyl group of the sugar (38). In the first mechanism, the amino group of each amino acid would ultimately be converted to ammonia and thus each amino acid would give the same distribution of pyrazine compounds and also the same product distribution as an ammonium salt heated with a carbohydrate. In the second mechanism, the ease of the initial nucleophylic attack would be influenced by the nature of the amino acid reactant and each amino acid would give different product distributions and product distributions different from an ammonium salt heated with glucose.

Figure 8 shows the product distribution for a number of amino acids and ammonium chloride heated with glucose in the model system. The results clearly showed that amino acids gave product distributions very 


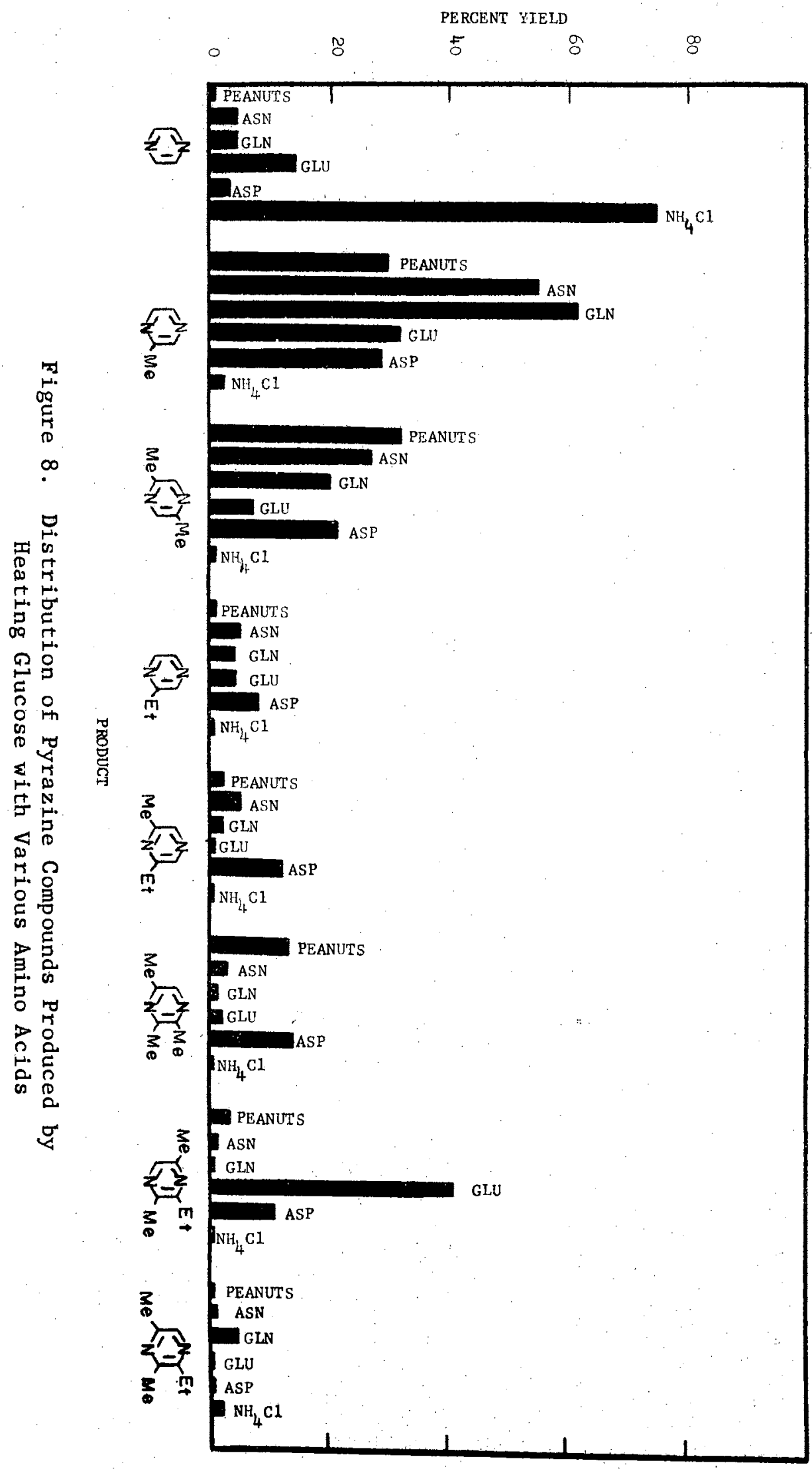


different from an ammonium salt when the nitrogen-containing reactant was heated with glucose. Amino acids gave 2-methylpyrazine as a major product; ammonium chloride gave more pyrazine. These facts ruled out the first mechanism for the production of pyrazines proposed above. The facts that the yield of 2,5-dimethylpyrazine was lower and that the yield of dimethylethylpyrazines was higher in the glutamic acid-glucose system than in the other systems studied indicated to the author that a two carbon fragment might have alkylated 2,5-dimethylpyrazine to increase the yield of the dimethylethyl derivative. This phenomenon was also suggested by the work of Stoehr (54). To determine if a two carbon fragment could effect the proposed alkylation reaction, a model system containing 10 mMoles of glucose, 10 mMoles of asparagine and a large excess of acetaldehyde was prepared. The total yield of pyrazines from this system is given in Table XIV. The product distribution shown in Figure 9 indicated that larger amounts of pyrazine and 2-methylpyrazine were formed in comparison to the product distribution in the absence of acetaldehyde. This was expected since all carbons of pyrazine and carbons 5 and 6 of 2-methylpyrazine probably can arise from two carbon fragments. Mass action would tend to increase the yield of these products in the presence of excess acetaldehyde. Figure 9 showed that the yield of 2-methy1-5-ethylpyrazine was increased many fold in the presence of added acetaldehyde; 2,6-dimethyl-3-ethylpryazine also increased but not as dramatically as the former derivative. These results strongly suggested the participation of a two carbon fragment, such as acetaldehyde, in the formation of ethyl substituted pyrazine compounds. It was impossible to determine from the data if the acetaldehyde added to the pyrazine or to a pyrazine precursor. 


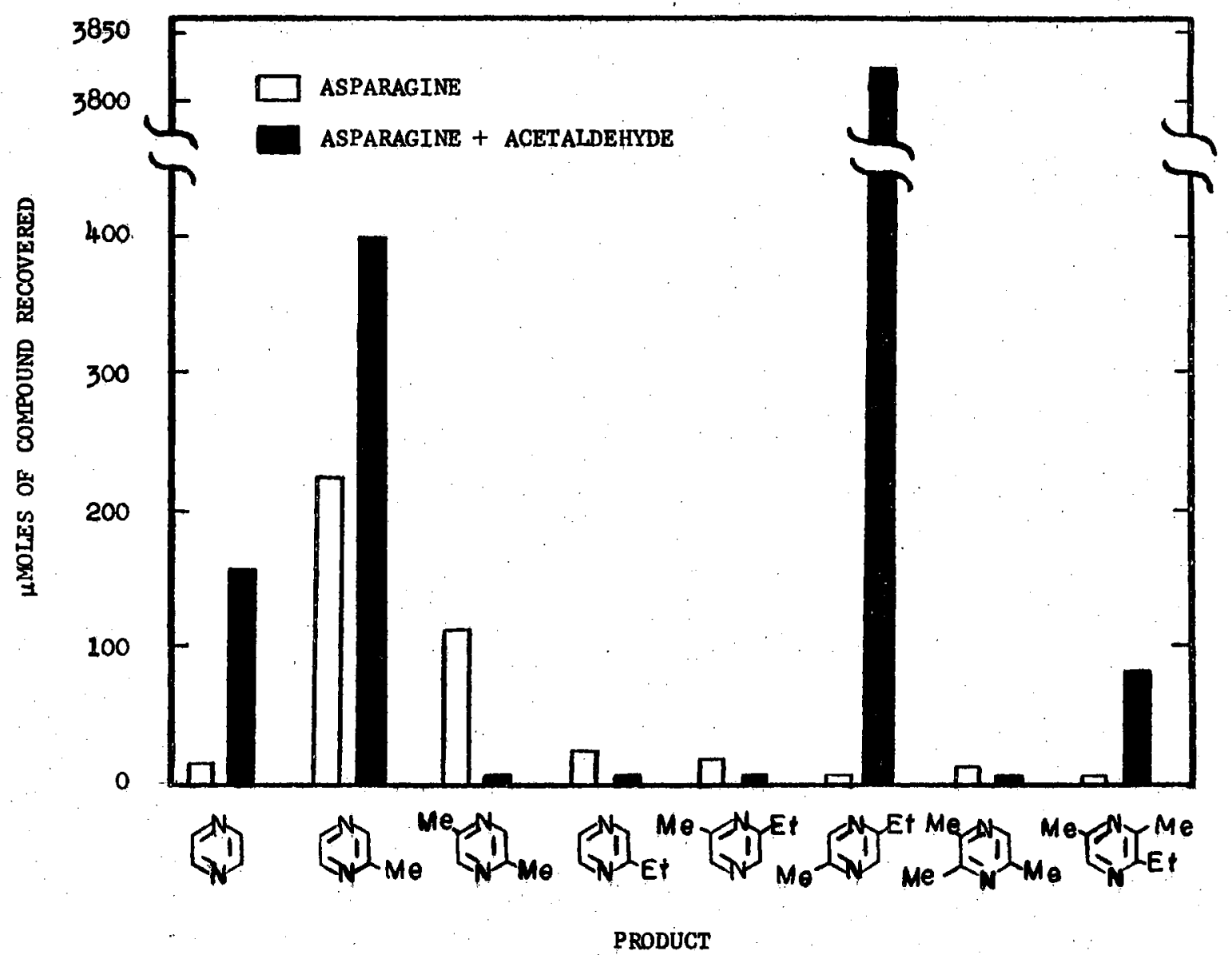

Figure 9. Effect of Adding Acetaldehyde to Model System Containing Glucose and Asparagine 
Sucrose is the major carbohydrate in peanut cotyledons (Chapter IV). The reaction of sucrose (10 mMoles) with asparagine (10 mMoles) was studied to determine if the sugar could serve as a reactant in the formation of pyrazines. Table XIV shows that sucrose gave a significant amount of ultraviolet absorbing material when heated with asparagine but not as much as did glucose under the same conditions. Figure 10 gives the product distribution for asparagine heated in the presence of glucose, sucrose, and fructose plus glucose in three separate experiments. The glucose and sucrose gave significantly different product distributions; fructose plus glucose gave nearly the same product distribution as sucrose, especially for the major products 2-methylpyrazine and 2,5dimethylpyrazine. The results suggested that sucrose was hydrolyzed to glucose and fructose prior to reaction with the amino acid to give pyrazines. The hydrolysis must have been incomplete since Table XIV shows that sucrose gave only about one-half as much ultraviolet absorbing material as an equimolar quantity of glucose. If 10 mMoles of sucrose were completely hydrolyzed, one would expect to obtain nearly twice as much ultraviolet absorbing material as with an equimolar quantity of glucose heated with asparagine.

Data in Figure 8 shows that no single amino acid when heated with glucose gave a product distribution the same as that from a falling film distillate of roasted peanuts. However, a mixture of amino acids (glutamic acid, aspartic acid glutamine, asparagine, and phenylalanine) and monosaccharides (glucose and fructose) which closely approximated the amino acid and carbohydrate analysis of good flavored raw peanuts, gave a distribution of products similar to roasted peanuts (Figure 11). The agreement was particularly good for 2-methylpyrazine, 


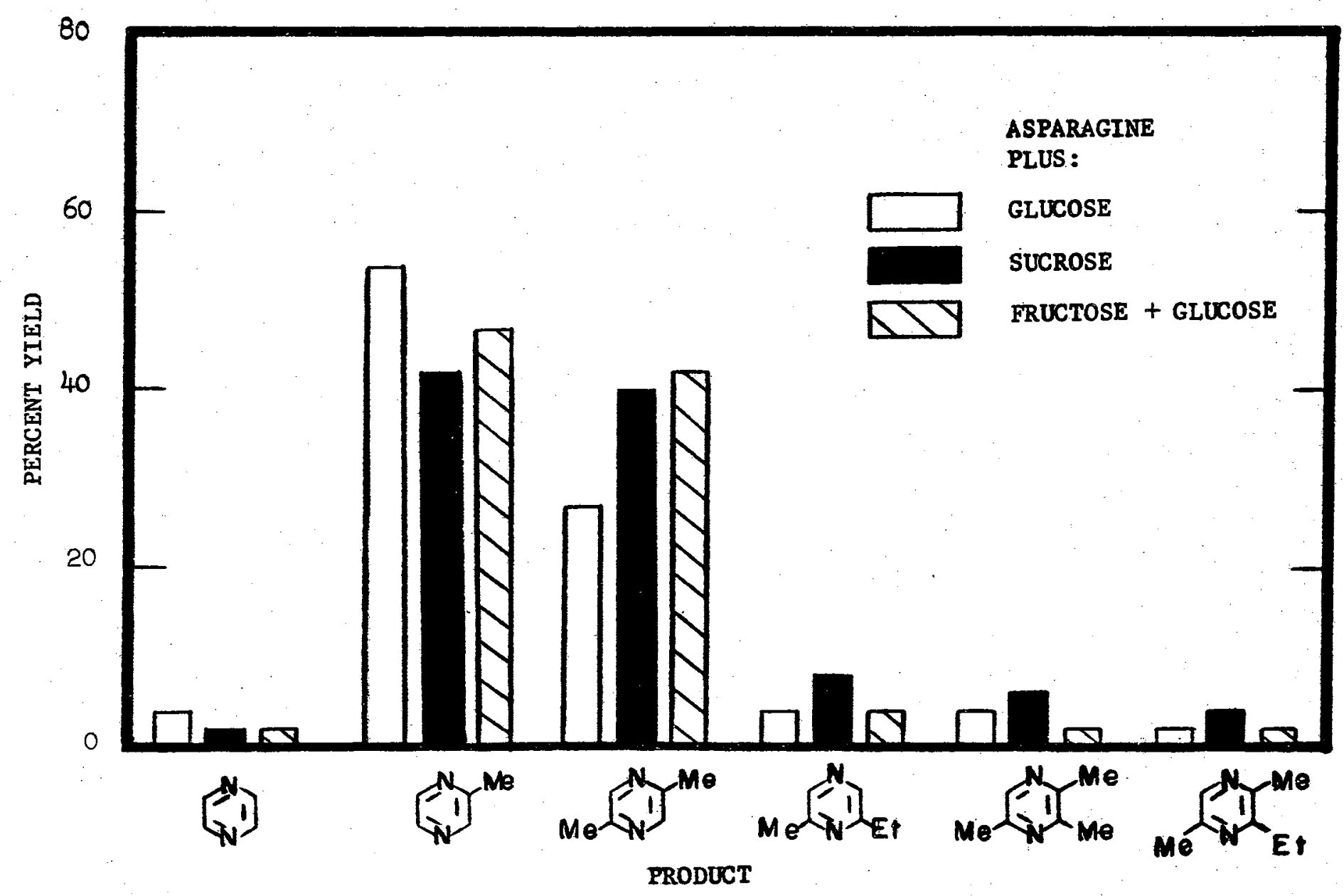

Figure 10. Distribution of Pyrazine Compounds Produced by Heating Asparagine with Various Carbohydrates 


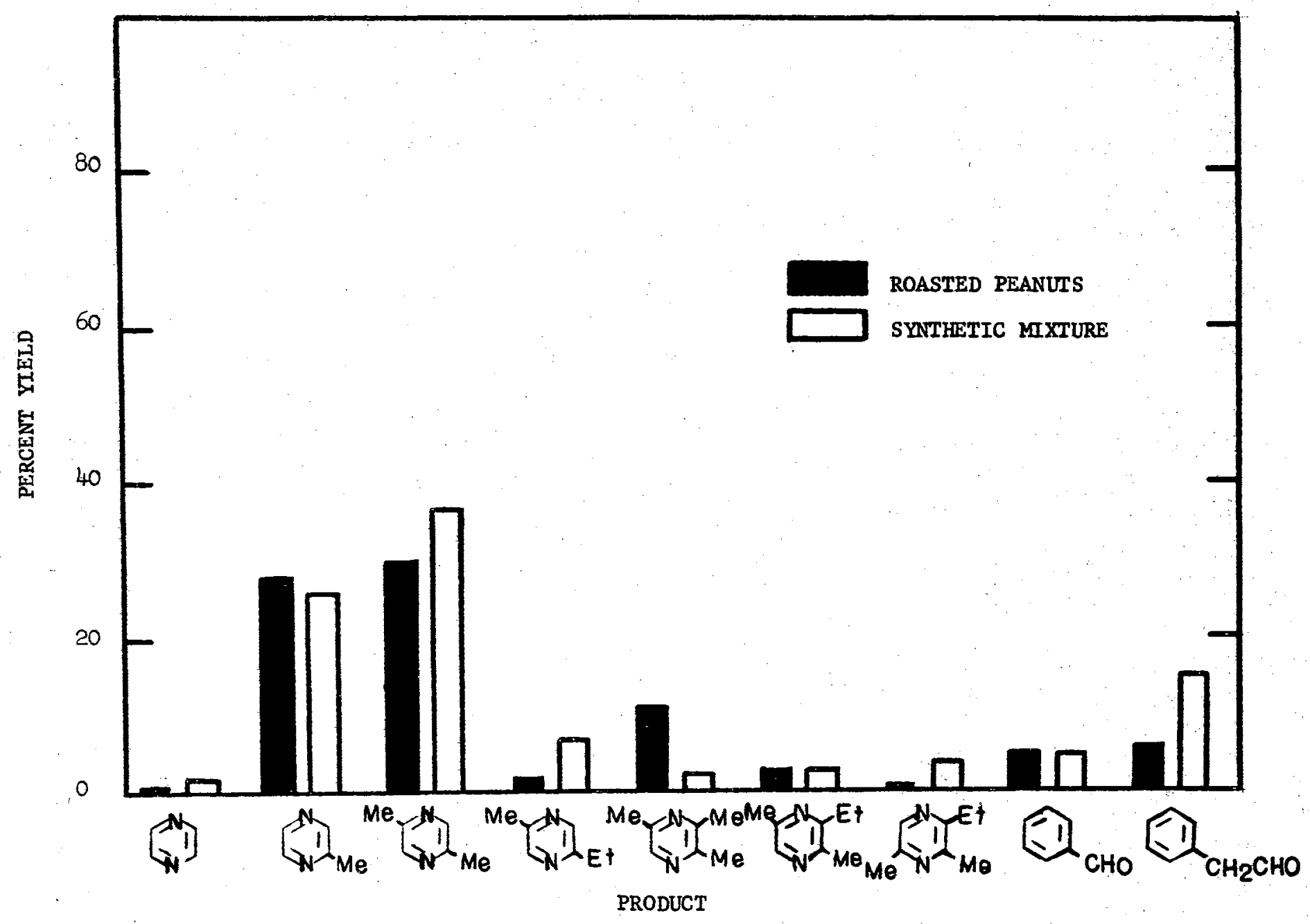

Figure 11. Pyrazines Produced from a Mixture of Amino Acids and Reducing Sugars which are Precursors of

Typical Flavor 
2,5-dime thylpyrazine, 2,5-dimethy1-3-ethylpyrazine, and benzaldehyde. It was assumed in preparing the peanut-1ike mixture of amino acids and monosaccharides that the ratio of aspartic acid to glutamic acid was the same as the ratio of asparagine to glutamine. This assumption was necessary since asparagine and glutamine could not be separated on the amino acid analyzer and thus could not be exactly quantitated.

Although glutamic acid forms pyrazines more slowly than the other amino acids studied, its contribution to the pyrazines of roasted peanuts is considerable since its concentration in raw peanuts is high. Table XV gives MMoles per pound of some precursors of typical peanut flavor and the MMoles of total pyrazines formed per hour in model systems containing the amino acid and glucose. The results indicated that the reaction of glutamic acid and glutamine with monosaccharides could account for nearly $87 \%$ of the volatile pyrazines formed during roasting of peanuts.

Results presented in this chapter showed that amino acids and sugars when heated together can form volatile pyrazine compounds. A peanut-1ike mixture of amino acids and monosaccharides produced pyrazines having a distribution similar to that found in roasted peanuts.

However, none of the mixtures of pyrazines isolated from the model systems had a truly characteristic roasted peanut aroma but rather had a roasted-nutty aroma. Raw peanuts must contain one or a series of as yet unknown flavor precursors which are responsible for the formation of volatile compounds which give roasted peanuts their characteristic "peanutty" aroma.

Since one can supress the peanut-like aroma of a distillate of roasted peanuts by acidification of the mixture, the compounds 
TABLE XV

APPARENT CONTRIBUTION OF VARIOUS AMINO

ACIDS TO TOTAL PYRAZINES FORMED

DURING ROASTING OF PEANUTS

\begin{tabular}{|c|c|c|c|c|}
\hline Compound & $\begin{array}{l}\text { Amino Acid } \\
\mu \text { moles/1b }\end{array}$ & $\begin{array}{l}\text { Moles Pyrazines } \\
\text { formed/hour/ } / \text { mole } \\
\text { Amino Acid }\end{array}$ & \multicolumn{2}{|c|}{ Contribution } \\
\hline Glutamic acid & 3180 & 4.4 & 13,992 & $57.4 \%$ \\
\hline Aspartic acid & 263 & 7.6 & 1,999 & $8.2 \%$ \\
\hline Glutamine & 915 & 7.8 & 7,137 & $29.3 \%$ \\
\hline Asparagine & 78 & 15.8 & 1,232 & $5.1 \%$ \\
\hline
\end{tabular}


responsible for the "peanutty" aroma of roasted peanuts must be basic compounds not unlike the pyrazines.

Amino acids and carbohydrates are among the precursors of roasted peanut flavor since, when heated together in a system of 1 ow water content, they produce many of the same volatile carbonyl and pyrazine compounds that are produced during normal roasting of peanuts. 


\title{
CHAPTER VII
}

\begin{abstract}
SUMMARY
Peanuts require a high temperature roasting process in order to develop the typical flavor associated with roasted peanuts. This fact implies that raw peanuts contain certain compounds of low volatility (flavor precursors) which are converted, during roasting, to other more volatile compounds (flavor components) which are responsible for the flavor of roasted peanuts.

Raw and roasted peanuts or heated and unheated soluble extracts of raw peanuts were analyzed for various classes of compounds. Compounds which decreased in concentration during heating were implicated as precursors of peanut flavor.

On1y amino acids and carbohydrates were observed to decrease significantly in concentration during roasting of peanuts. Analysis of peanuts of known flavor for individual amino acids and carbohydrates resulted in the derivation of an equation which related amino acid flavor precursor concentration to subjectively measured flavor of roasted peanuts. Calculations on the basis of this equation indicated that aspartic acid, glutamic acid, glutamine, asparagine, histidine and phenylalanine were associated with the production of typical peanut flavor; threonine, tyrosine, lysine and an unknown amino acid we re considered to be precursors of atypical flavor.

The concentration of precursors of typical flavor increased during
\end{abstract}


maturation; precursors of atypical flavor decreased in concentration during the same period.

Amino acids associated with the production of typical peanut flavor were heated with carbohydrates in a nearly non-aqueous model system. The same volatile compounds produced during roasting of peanuts were produced in the model systems. 
1. Lepkovsky, S., Food Technology, 20, 50 (1966).

2. Barnes, T. C., Abstracts of papers, Am. Psycol. Assoc., Cincinnati, Ohio, Sept. 7, 1959.

3. Moncrieff, R. W., The Chemical Senses, John Wiley and Sons, Inc., New York, 1944.

4. Thulin, W. W., Kuramoto, S., Food Technology, 21, 64 (1967).

5. Pickett, T. A., Holley, K. T., Peanut Roasting Studies, Georgia Expt. Sta. Tech. Bull. No. 1, 1952.

6. Hoffpauir, C. L., J. Agr. and Food Chem., 1, 668 (1953).

$\checkmark$ 7. Mason, M. E., Waller, G. R., J. Agr, and Food Chem., 12, 274 (1964).

$\checkmark$ 8. Pickett, T. A., Some Effects of Heat Treatment of Peanuts, Georgia Expt. Sta. Cir. 142, 1943.

9. Pickett, T. A., The Peanut Journal and Nut Wor1d, 26 (1947).

10. Thaler, H., Gaig1, R, Z. Lebensm. Untersuch. u.-Forsch., 120 , 357 (1963).

11. Pattee, H. E., Beasley, E. O., Singleton, J. A., J. Food Sci., 30, 388 (1965).

12. Young, C. T., Holley, K. T., Comparison of Peanut Varieties in Storage and Roasting, Georgia Expt. Sta, Tech, Bull. N. S. 41, April, 1965 .

13. Mason, M. E., Johnson, B., Hamming, M. C., J. Agr . and Food Chem., 14, 454 (1966).

14. Mason, M. E., Johnson, B., Hamming, M. C., J, Agr and Food Chem., 15, 66 (1967).

15. Mason, M. E., Johnson, B., Hamming, M. C., Ana1, Chem., 37, 760 (1965).

16. Deck, R. E., Chang, S. S., Chem, and Ind., 1343 (1965).

17. Rohan, T. A., J. Sci. Food Agr., 14, 799 (1963). 
18. Rohan, T. A., J. Food Sci., 29, 456 (1964).

19. Rohan, T. A., Conne11, M., J. Faod Sci., 29, 460 (1964).

20. Rohan, T. A., Stewart, T., J. Food Sci., 30, 416 (1965).

21. Rohan, T. A., Stewart, T., J. Food Sci., 31, 202 (1966).

22. Schonberg, A., Moubasher, R., Chem. Revs., 50, 261 (1952).

23. Schonberg, A., Moubasher, R., Moustafa, J. Chem. Soc., 163 (1948).

24. Pinto, A., Chichester, C. 0., J. Food Sci., 31, 726 (1966).

25. Rohan, T.A., Stewart, T., J. Food Sci., 31, 206 (1966).

26. Herz, W. J., Shallenberger, R. S., Food Research, 25, 491 (1960).

27. Forsyth, W. G. C., Quesne1, V. C., in "Advances in Enzymology," F. F. Nord, ed., Vo1. XV, pp. 457, New York and London, Interscience Publishers--John Wiley and Sons, 1963.

28. Reichstein, T., Staudinger, H., Angew. Chem., 62, 292 (1950).

29. Goldman, I. M., Seib1, J., Flament, I., Gautschi, F., Winter, M., Willhalm, B., Stoll, M., Helv. Chim. Acta, 50, 694 (1967).

30. Dawes, I. W., Edwards, R. A., Chem, and Ind., 2203 (1966).

31. Heyns, K., Paulsen, H., Wiss. Veroeffent1. Deut. Gas. Ernaehrung, 5, 15 (1960).

32. Danehy, J. P., Pigman, W. W., Adv. In Food Res., 3, 241 (1951).

33. Reynolds, T. M., Adv. in Food Res., 12, 1 (1963).

34. Reynolds, T. M., Adv. in Food Res., 14, 167 (1965).

35. Elis, G. P., Adv. in Carbohydrate Chem., 14, 63 (1959).

36. Anet, E. F. L. J., Adv. in Carbohydrate Chem., 19, 181 (1964),

37. Hodge, J. E., J. Agr. and Food Chem., 1, 928 (1953).

38. Song, P., Chichester, C. 0., J. Food Sci., 31, 914 (1966).

39. Song, P., Chichester, C. 0., Stadtman, F. H., J. Food Sci., 31, 906 (1966).

40. Katchalsky, A., Sharon, N., Biochim. et Biophys. Acta., 10, 290 (1953).

41. Hodge, J. E., Rist, C. E., J. Am. Chem. Soc., 74, 1414 (1952). 
42. Gottscha1k, A., Biochem. J., 52, 445 (1952).

43. Godge, J. E., Rist, C. E., J. Am. Chem. Soc., 75, 316 (1953).

44. Mackinney, G. "Contributions of Browning Research to Ration Item Stability," pp. 21, Chicago, Ill., Research and Development Associates, Food and Container Institute, Inc., 1952.

45. Rice, R. G., Kertesz, Z. I., Stotz, F. H., J. Am, Chem. Soc., 69, 1798 (1947).

46. Hodge, J. E., in Symposium on Foods: Chemistry and Physiology of Flavor, ed. H. W. Schultz, AVI Publishing Co., Westport, Coni., 1965.

47. Speck, J. C. "Contributions of Browning Research to Ration Item Stability," pp. 29, Chicago, Ill., Research and Development Associates, Food and Container Institute, Inc,, 1952.

48. Akabori, S., Ber., 66, 143 (1933).

49. Stadtman, F. H., Chichester, C., Mackinney, G., J. Am. Chem. Soc., 74, 3194 (1952).

50. Mohammad, A., Olcott, H. S., Fraenkel-Conrat, H., Arch. Biochem, 24, 270 (1949).

51. Wolfrom, M. L., Schlicht, R. C., Langer, A. W., Rooney, C. S., J. Am. Chem. Soc., 75, 1013 (1953).

52. Etard, A., Compt. Rend., 92, 460, 795 (1881).

53. Stoehr, C., J. Prakt. Chem., 47, 439 (1893).

54. Stoehr, C., J. Prakt. Chem., 51, 445 (1895).

55. Brandes, P., Ștoehr, C., J. Prakt. Chem., 54, 481 (1896).

56. Stolte, K., Biochem. Z., 12, 499 (1908).

57. Tanret, C., Bul1. Soc. Chim., 44, 102 (1885).

58. Wiggins, L. F., Proc. Cong. Intern. Soc. Sugar Cane Technologists (9th) British West Indies, p. 525 (1956).

59. Stiles, H. R., U. S. Patent 2,603,567 (1951).

60. Hough, L., Jones, J. K. N., Richards, E. L., J. Chem, Soc., 3854 (1952).

61. Lobry du Bruyn, Rec, Trav. Chim., 18, 72 (1899).

62. Stolte, K., Chem. Zentr. I., 224 (1908), 
63. Hurd, C. D., "Contributions of Browning Research to Ration Item Stability," pp. 21, Chicago, I11., Research and Development Associates, Food and Container Institute, Inc., 1952.

64. Johnson, M. J., J. Bio1. Chem., 181, 707 (1948).

65. Hunter, I. R., Dinick, K. P., Corse, J. W., Chem. Ind. (London), 294 (1956).

66. Wilkin, D. R., Hansen, R. G., J. Biol. Chem., 236, 1051 (1961).

67. Spackman, D. H., Stein, W. H., Moore, S., Ana1. Chem., 30, 1190 (1958).

68. Moore, S., Spackman, H., Stein, W. H., Ana1. Chem,, 30, 1185 (1958).

69. Moore, S., Stein, W. H., J. Biol. Chem., 211, 907 (1954).

70. Ra11s, J. W., Ana1. Chem., 32, 332 (1960).

71. Sweeley, C. C., Bentley, R., Makita, M., Wells, W. W., J. Am. Chem. Soc., 85,2497 (1963).

72. Furuholmen, A. M, Winefordner, J. D., Dennison, R. A., Knapp, F, W., J. Agr. and Food Chem., 12, 112 (1964).

73. Iverson, J. L., Firestone, D., Horowitz, W., J. Assn. Off.. Agr. Chemists, 46,718 (1963).

74. Casey, J. C., Self, R., Swain, T., J. Food Sci., 30, 33 (1965).

75. Johnson, B., "Isolation and Identification of Some Volatile Constituents of Roasted Peanuts," (M. S. dissertation, Oklahoma State University, 1966).

76. Gilpin, J. A., Mclafferty, F. W., Anal. Chem., 29, 990 (1957).

77. Mejbaum, W., Z. Physol. Chem., 258, 117 (1939).

78. Colvin, H. W., Atteberry, J. T., Ivy, J. T., J. Dairy Sci., 44, 2081 (1961).

79. Nelson, N., J. Biol. Chem., 153, 375 (1944).

80. Robinson, H. W., Hogden, C. G., J. Biol. Chem., 135, 727 (1940).

81. Greenstein, J. P., Winitz, M., "Chemistry of the Amino Acids," pp. 1933, Wiley, New York and London, 1961.

82. El'ode, T. E., Dornseifer, T. P., Keith, E. S., Powers, J. J., J. Food Sci., 31, 351 (1966).

83. Herz, K. O., Chang, S. S., J. Food Sci., 31, 937 (1966). 
VITA

Jon Albert Newe11

Candidate for the Degree of

Doctor of Philosophy

Thesis: PRECURSORS OF TYPICAL AND ATYPICAL ROASTED PEANUT FLAVOR

Major Field: Chemistry

Biographical:

Personal Data: Born in St. Louis, Missouri, August 5, 1941, the son of Albert F. and Beulah E. Newe11. Married Andrea L. Loyd of Bartlesville, Oklahoma, in Stillwater, Oklahoma,

December 18, 1964 .

Education: Attended grade school in Webster Groves, Missouri; graduated from Enid High School, Enid, Oklahoma, in 1959; received the Bachelor of Science degree in chemistry from Oklahoma State University in August, 1963. Completed the requirements for the Doctor of Philosophy degree in July, 1967.

Professional Experience: Undergraduate Research Assistant, Department of Biochemistry, Oklahoma State University from January, 1961, to August, 1963; Laboratory technician at the Enid Board of Trade Laboratory, Enid, Oklahoma, during the summers of 1960 to 1962; Graduate Assistant in the Department of Biochemistry, Oklahoma State University, September, 1963, to July, 1967.

Professional and Honorary Societies: Member of: Phi Eta Sigma, Phi Lambda Upsilon, Sigma Xi, and the American Chemical Society.

Awards: Recipient of the 1966-67 Nestlé Fellowship in Food Science. 